\title{
GRUPOS EMPRESARIALES EN LA ESPAÑA CONTEMPORÁNEA: EL GRUPO URQUIJO, 1851-1982*
}

\author{
BUSINESS GROUPS IN \\ CONTEMPORARY SPAIN: URQUIJO GROUP, \\ 1851-1982
}

\author{
Núria Puig Raposo y Eugenio Torres Villanueva \\ Universidad Complutense, Madrid, España; nuriapuig@ccee.ucm.es; eugen@cps.ucm.es
}

Resumen. En este artículo se examina la trayectoria histórica del grupo Urquijo, uno de los grupos empresariales más importantes de España en el siglo Xx. Se trata de un ejemplo representativo del modelo de grupos empresariales creados por algunos bancos mixtos en España entre finales del siglo XIX y principios del XX. El trabajo enfatiza la importancia de este tipo de organización económica en el desarrollo industrial del país, al promover la creación de empresas y garantizar su crecimiento a largo plazo mediante el aporte de tres recursos esenciales: financiación permanente, capacidad tecnológica procedente del exterior y capital humano cualificado (técnicos y directivos).

Palabras clave: grupos empresariales; banca industrial; siglos XIX y XX; España.

Abstract. This article examines the historical evolution of Urquijo, one of the largest business groups in 20th century Spain. Urquijo constitutes a representative example of business organizational model created by some Spanish universal banks in the late nineteenth and early twentieth centuries. The article shows that this type of economic organization played a significant role in Spain's industrial development by promoting entrepreneurship and ensuring its long-term growth through the provision of three essential resources: permanent funding, imported technological capabilities, and technical and managerial human capital.

Key words: business groups; merchant banking; 19th y 20th centuries; Spain.

Fecha de recepción: 6 de mayo de 2014. Fecha de aceptación: 8 de julio de 2014.

* Para la realización de este artículo se recibió financiación del Ministerio de Ciencia e Innovación de España (Proyecto de Investigación ECO2009-10977).

Am. Lat. Hist. Econ., año 22, núm. 2, mayo-agosto, 2015, pp. 160-197 


\section{INTRODUCCIÓN}

$\mathrm{L}$

os grupos empresariales o económicos (business groups) representan formas distintas de organización de los negocios a las de una empresa individual independiente y sobre todo de la gran empresa chandleriana. Se trata de estructuras organizativas constituidas por un número más o menos amplio de empresas legalmente autónomas pero vinculadas entre sí financiera, organizativa o estratégicamente, que desarrollan su actividad en un amplio abanico de sectores no siempre relacionados. La numerosa literatura existente sobre ellos ha destacado su gran diversidad y presencia, históricamente hablando, tanto en países desarrollados como en otros que no lo son tanto (Colpan, Hikino y Lincoln, 2010). El caso que analizamos en este artículo muestra, precisamente, cómo el modelo de grupo adoptado por el Banco Urquijo en España, un país atrasado, estuvo influido, desde las décadas finales del siglo XIX, por grupos similares existentes en países europeos más avanzados económicamente, como Francia, Alemania y Reino Unido.

Desde la perspectiva de la historia empresarial, en la que se enmarca este artículo, los grupos no son sólo manifestaciones de la organización de los negocios del presente. Son también formas organizativas forjadas a lo largo del tiempo en simbiosis con los modos de organización social y política y los valores culturales predominantes en cada país, condicionadas por la dotación relativa de factores de producción. Estudiarlos desde el punto de vista histórico permite entender cómo aparecieron, cómo forjaron sus señas de identidad, cómo se adaptaron a los cambios del entorno y cómo influyeron en el desarrollo económico de sus países.

En este trabajo se examina la trayectoria histórica del grupo empresarial privado más importante de España en el siglo XX, el grupo Urquijo. Se trata de un grupo familiar (fundado y gestionado por la familia Urquijo) y bancario (su núcleo organizativo y estratégico fue una entidad bancaria), que reúne así las dos características más frecuentes en los grupos empresariales españoles que, desde finales del siglo XIX en adelante, fueron de manera predominante grupos bancarios o grupos familiares, o ambas cosas a la vez. Los grupos empresariales españoles han sido relativamente poco estudiados por los historiadores económicos. En el caso de los grupos bancarios, una línea de investigación pionera, basada en el análisis de los consejeros comunes (Muñoz, 1970), estuvo largo tiempo olvidada (Pueyo, 2006). Más recientemente el interés mostrado radica en los grupos de carácter familiar (Valdaliso, 2004 y 2006).

Siguiendo las hipótesis de Gerschenkron (1968) sobre el atraso económico de los países, podemos decir que, en la España de finales del siglo XIX, la aparición de esta clase de grupos empresariales puede conside- 
rarse como uno de los "instrumentos institucionales", ${ }^{1}$ los otros fueron el Estado y la banca mixta (comercial y de fomento de la industria), de los que se dotaron, según este autor, los países europeos que históricamente se retrasaron respecto a sus vecinos en cuanto a desarrollo económico. $\mathrm{Su}$ finalidad fue crear condiciones y movilizar los recursos internos para el desarrollo, como el ahorro y el capital humano, pero también captar en el exterior, en los países desarrollados, el capital y la tecnología de los que se carecía.

Las hipótesis de Gerschenkron iluminan, cuando menos, el origen de los grupos empresariales españoles conocidos como grupos bancarios, es decir, grupos constituidos en torno a bancos de carácter mixto que desarrollaron, además de las actividades propias de la banca comercial y de depósito, financiamiento de industrias y promoción de empresas. Aunque esta banca mixta no apareció con sus rasgos bien definidos hasta principios del siglo XX, su origen a pequeña escala podemos rastrearlo en los banqueros particulares y en las casas de banca familiares existentes en España desde mediados del siglo XIX al menos, algunas de las cuales se convirtieron, ya en el siglo $\mathrm{XX}$, en bancos con una apreciable vocación de fomento a la industria. Aunque no es el único, el caso de Urquijo y Compañía y de su sucesor, el Banco Urquijo, es seguramente el más representativo de todos por la persistencia durante más de un siglo de su compromiso con el fomento a la industria y por la dimensión e importancia del grupo empresarial que creó.

El contenido del artículo sintetiza algunos de los resultados de la investigación que los autores han realizado en los últimos años sobre el grupo Urquijo (Puig y Torres, 2008, 2011). ${ }^{2}$ El hilo argumental lo constituye la estrategia de crecimiento a largo plazo del grupo y el tipo de sectores productivos en los que se implantó, así como las empresas más representativas que promovió en cada etapa. Complementariamente, se explican los principales cambios que esta estrategia provocó en la organización y la gestión del Banco Urquijo, resaltando la continuidad de la familia fundadora a lo largo de cinco generaciones.

Se ha utilizado documentación procedente de fuentes internas del grupo Urquijo (libros de actas de las juntas generales de accionistas, del consejo de administración y de otros órganos de gobierno del Banco Urquijo)

\footnotetext{
${ }^{1}$ Gerschenkron no incluyó expresamente a los grupos empresariales entre los "instrumentos institucionales", pero sí apuntó a los elementos de esta clase que pudieran existir en la esfera de la organización y la dirección de los negocios.

${ }^{2}$ Existe una versión previa en línea del X Congreso Internacional de la Asociación Española de Historia Económica, del 8 al 10 de septiembre de 2011, Universidad Pablo de Olavide, Carmona (Sevilla) http://www.aehe.net/xcongreso/pdf/sesiones/grupo/el\%20grupo\%20urquijo\%20 y\%20el\%20desarrollo\%20economico.pdf
} 
y externas (memorias de este y de las empresas participadas más representativas, informes publicados por el Servicio de Estudios, etc.). Asimismo, se ha empleado información procedente de entrevistas a ex directivos del Banco Urquijo, de publicaciones periódicas (anuarios financieros y de sociedades anónimas) y de la amplia bibliografía disponible sobre empresas y sectores en los que estuvo presente el grupo Urquijo.

\section{Fundación dE la CASA de BANCA URQujo (1851-1870)}

El origen del grupo Urquijo se sitúa en 1851, cuando el fundador de la dinastía familiar de los Urquijo, Estanislao Urquijo Landaluce (1816-1889), oriundo de la provincia de Álava, se estableció en Madrid como banquero particular. Partiendo prácticamente de la nada y gracias al apoyo de la red de familiares y parientes que lo acogió en la capital de España a su llegada en 1829, así como a sus capacidades personales, Urquijo desarrolló una sólida carrera profesional en el mundo de las finanzas, al ejercer de agente de bolsa (1843-1851) y trabajando de empleado (1835-1848) en la oficina madrileña de la Casa Rothschild, una de las principales firmas bancarias extranjeras con fuertes inversiones en España durante el siglo XIX, y uno de los ejemplos más representativos de lo que era entonces la banca de negocios (merchant banking) en Europa. Todo ello le permitió aprender el oficio de banquero, así como adquirir una notable experiencia financiera, un buen conocimiento del mundo de los negocios madrileño y, en particular, del mercado de capitales y de sus protagonistas; un bagaje que le resultó de utilidad para gestionar prudente y eficazmente su propio negocio bancario.

Entre 1851 y 1870 Urquijo realizó negocios que sirvieron para que su casa de banca se hiciese un hueco en el mercado madrileño de capitales y sentar las bases de su posterior desarrollo. Dichos negocios podemos clasificarlos en tres categorías: en primer lugar, están los préstamos a particulares con garantía hipotecaria, operaciones que llevaban aparejada cierta especulación inmobiliaria. Aunque la mayoría fue de cuantías modestas, los grandes negocios inmobiliarios en los que tomó parte Urquijo están relacionados con el marqués de Salamanca, al que financió en su proyecto de construcción del barrio del mismo nombre en el ensanche de Madrid. Los apuros financieros que el marqués atravesó en este negocio lo obligaron a que hipotecara y vendiera muchos de los edificios construidos, o en construcción, lo que permitió a sus acreedores -Urquijo entre ellos- hacerse de gran parte de los mismos, enajenándolos posteriormente. Asimismo, financió al duque de Osuna y se convirtió en uno de los principales acreedores en la posterior quiebra de la Casa Osuna, dueña de una de las 
mayores fortunas de España. Una estimación incompleta del montante de los créditos hipotecarios concedidos por Urquijo entre 1851 y 1873, supera los 65000000 de reales (Rueda, 1996, pp. 308-309).

En segundo lugar, están los anticipos y préstamos al Tesoro Público, acuciado de forma crónica por el déficit. Se trata de negocios muy lucrativos para los prestamistas que apuraban al máximo sus ventajas frente a gobiernos con débil poder de negociación a causa de sus imperiosas necesidades financieras. Por otro lado, era una clase de negocios con los que Urquijo se familiarizó mientras estuvo al servicio de la Casa Rothschild. Estas operaciones se realizaron después de la revolución de 1868, en un ambiente de buenas relaciones con los políticos liberales en el poder, y alcanzaron su máxima cuantía (más de 700000000 de reales en anticipos y otros 600000000 en deuda consolidada) en 1871 y 1872, durante el reinado de Amadeo I de Saboya. En todas ellas colaboraron otras casas bancarias y prestamistas particulares (el denominado Sindicato de Madrid), liderados por Urquijo, que elevó notablemente su reputación profesional en el mercado de capitales madrileño, además de ser ennoblecido con el marquesado de Urquijo por el citado rey en 1871.

Por último, en tercer lugar, está su participación en empresas importantes al aportar su capital y su experiencia bancaria. Lo hizo habitualmente en compañía de otros socios, con los que mantenía relaciones profesionales en el mercado de capitales madrileño, y siempre en un plano secundario, nunca principal. Esto sucedió en el marco de la legislación sobre ferrocarriles, por un lado, y sobre bancos de emisión y sociedades de crédito (1855-1856), por otro, cuya aplicación favoreció el desarrollo de importantes iniciativas de promoción de negocios por parte del capital francés, así como la creación del Banco de España como banco de emisión en 1856. Urquijo fue accionista y miembro del consejo de administración de esta entidad desde el principio. En paralelo, participó en dos importantes iniciativas de la Casa Rothschild en el sector ferroviario. Una era la Sociedad Española Mercantil e Industrial, de la que fue cofundador y consejero hasta su disolución en 1868; la otra era la Compañía de los Ferrocarriles de Madrid-Zaragoza-Alicante, una de las grandes firmas del sector, que fue promovida a su vez por la Sociedad Española Mercantil e Industrial en 1856. Ya como accionista, Urquijo formó parte de su consejo en 1875. Por último, a finales de 1872, está su participación en la fundación del Banco Hipotecario de España por iniciativa de entidades francesas (Paribas, ${ }^{3}$ Credit Foncier y Societé Générale, entre otras), relacionadas, a su vez, con el Banco de Castilla (Rodrigo, 2001, p. 8; Castro, 2010, pp. 51-65). El Banco Hipotecario, del que Estanislao Urquijo poseía al morir,

\footnotetext{
${ }^{3}$ Banco de París y de los Países Bajos.
} 
en 1889, 2500 acciones y 1830 obligaciones (Rueda, 1996, p. 299), recibió por parte del Estado el privilegio de emisión de cédulas hipotecarias durante 99 años. Estanislao no llegó a formar parte del consejo de administración de este banco, pero sí lo hizo su sobrino y sucesor Juan Manuel Urquijo en 1876.

En resumen, Estanislao Urquijo Landaluce no creó el grupo Urquijo como tal, pero sí el tipo de negocio bancario sobre el que este se asentó y desarrolló después, así como algunas de sus más distintivas señas de identidad: el carácter aristocrático y la relación estrecha, fluida y pragmática con el poder político. Su ascenso social, paralelo a su éxito en el mundo de los negocios, le permitió integrarse en la elite madrileña (aristócratas, hombres de negocios y políticos) y fortalecer los contactos y relaciones con sus miembros. Además, tuvo una participación activa en la política como diputado y senador, y logró establecer y afianzar contactos estrechos con numerosos políticos (parlamentarios, ministros o presidentes de gobierno), lo que le permitió influir en los gobiernos españoles de su época. Sus ideas políticas liberales no le impidieron ser pragmático: estuvo siempre junto al poder constituido, cualquiera que fuese (Díaz, 1998).

\section{CREACión DE LAS BASES DEL GRUPO URQUiJo (1870-1914)}

El protagonismo de esta etapa recae en el segundo marqués de Urquijo, Juan Manuel Urquijo Urrutia (1843-1914), sobrino y heredero del fundador, ya que este falleció soltero y sin descendencia directa en 1889. Los negocios de la familia Urquijo estuvieron a su cargo entre 1870 y 1914. Secundado por su tío, en 1870 le dio una constitución formal (sociedad regular colectiva) a la casa de banca familiar, que adoptó diversas razones sociales (véase cuadro 1) a medida que cambiaban los socios que tuvo. El segundo marqués asoció los negocios de la casa a familiares y parientes próximos: su hermano Lucas Urquijo (Urquijo Hermanos) y su cuñado Luis Ussía Aldama (Urquijo y Compañía), pero desde 1905 la propiedad y el control de la casa de banca familiar recayó exclusivamente en él y en sus tres hijos varones: los hermanos Urquijo Ussía.

Bajo el liderazgo de Juan Manuel Urquijo Urrutia, la Casa Urquijo continuó las operaciones bancarias ${ }^{4}$ que había hecho desde 1851, pero gradualmente ganaron peso otras nuevas como el crédito a medio y largo plazo y la adquisición de valores (acciones y obligaciones) emitidos por

\footnotetext{
${ }^{4}$ Operaciones de bolsa, descuentos de letras sobre provincias, préstamos a corto plazo con garantía hipotecaria o de valores, anticipos y créditos al Tesoro Público, arbitrajes y cambios, etcétera.
} 
CUADRO 1. RAZÓN SOCIAL DE LA CASA DE BANCA URQUIJO, 1870-1917

\begin{tabular}{llc}
\hline Razón social & \multicolumn{1}{c}{ Socios } & Años de vigencia \\
Urquijo y Arenzana & Benito Arenzana Echarri & $1870-1879$ \\
Urquijo Hermanos & Lucas Urquijo Urrutia & $1879-1883$ \\
Urquijo y Compañía & Luis Ussía Aldama & $1883-1905$ \\
Urquijo y Compañía & Estanislao, Juan Manuel & \\
& y Luis Urquijo Ussía & $1905-1917$ \\
\hline
\end{tabular}

Fuente: elaboración propia con base en Díaz (1998, pp. 152-159).

sociedades anónimas de diferentes sectores productivos, lo que supuso una nueva orientación de la Casa hacia la captación de este tipo de nuevos clientes y, en definitiva, hacia la financiación del proceso de industrialización del país. Era, en todo caso, una estrategia que suponía una participación activa ${ }^{5}$ en la promoción y desarrollo de empresas industriales, muchas de ellas líderes en su respectivo sector.

Esta estrategia permitió crear las bases del grupo Urquijo, considerado como el conjunto de empresas en las que la Casa Urquijo mantenía una participación significativa en el financiamiento básico (acciones y obligaciones) y el control -en solitario o compartido- de su gestión; se materializó en gran medida como resultado de la colaboración del segundo marqués de Urquijo en las iniciativas inversoras de banqueros y empresarios franceses (Crédito Mobiliario, Paribas) y españoles (los hermanos Girona, el marqués de Comillas, Evaristo Arnús, la familia Ybarra) que contaban con importantes intereses en los ferrocarriles, con los que la Casa Urquijo mantenía estrechos vínculos profesionales. La estrategia también se vio favorecida por el contexto de estabilidad política e institucional que vivió España en los cuatro decenios posteriores a la restauración de la monarquía borbónica en 1875 . Durante este periodo se intensificó el proceso de industrialización, en especial en regiones como Asturias y el País Vasco, donde estaban localizadas las principales minas de carbón y hierro, lugares en que se establecieron las mayores empresas siderometalúrgicas y de fabricación de bienes de equipo, todo esto al calor de las ventajas derivadas de la política económica proteccionista posterior al arancel de 1891 .

${ }^{5}$ No sólo aportando financiación, sino también con la participación en su gestión. 
La Casa Urquijo aportó financiación básica, además de créditos, a empresas de nueva creación en cuya gestión participó; todas ellas fundadas en el periodo analizado y, asimismo, las de mayor tamaño. Casi todas se encuentran entre las 200 mayores sociedades españolas (según el activo neto) en 1917 (Carreras y Tafunell, 1993). Sólo la Compañía de los Caminos de Hierro del Norte de España, la otra gran empresa ferroviaria junto con la Compañía de los Ferrocarriles de Madrid-Zaragoza-Alicante, había sido fundada con anterioridad. Juan Manuel Urquijo entró en el capital de esta compañía hacia 1880, momento a partir del cual se adhirió a la estrategia de penetración en el sector siderúrgico y de bienes de equipo (material móvil ferroviario) emprendida por los grandes accionistas de Norte (el Crédito Mobiliario Español, los hermanos Girona y el grupo Comillas) (véase cuadro 2).

Todos ellos participaron en 1882 en la fundación de Altos Hornos de Bilbao, que se transformó en Altos Hornos de Vizcaya en 1902, y en la creación, en 1908, de la Sociedad Española de Construcción Naval. En este último caso no participó el Crédito Mobiliario Español, convertido en el Banco Español de Crédito (Banesto) en 1902. También participaron en la constitución de Duro Felguera, la gran empresa minera y siderúrgica asturiana, aunque su presencia en la misma no sobrepasó la primera década del siglo xx. Para la Casa Urquijo, esta estrategia le permitió asentarse firmemente en el sector siderúrgico debido a que mantuvo un peso relativamente importante en Altos Hornos de Vizcaya y al control que ejerció sobre Duro Felguera a partir de 1907.

Además, su posición en la fabricación de bienes de equipo se fortaleció con la fundación en 1901 de la Sociedad Española de Construcciones Metálicas y en 1917 de la Compañía Auxiliar de Ferrocarriles, empresas que controló desde el principio. Paralelamente, elevó su participación accionaria en la Compañía de los Caminos de Hierro del Norte de España y la Compañía de los Ferrocarriles de Madrid-Zaragoza-Alicante: en la primera poseía 2.5\% del capital en 1917, mientras que en la segunda tenía 7\% en 1913 (Vidal, 1999, pp. 631-639; Comín, Martín, Muñoz y Vidal, 1998 , p. 320). Por otra parte, destaca su entrada en el sector eléctrico (producción, distribución y comercialización de electricidad) con la fundación de la Unión Eléctrica Madrileña, empresa controlada por la Casa Urquijo desde su nacimiento, que contribuyó notablemente a organizar de forma oligopolista el mercado eléctrico madrileño. ${ }^{6}$

\footnotetext{
${ }^{6}$ Parte de su capital era de origen francés (grupo Pereire) procedente de la extinta Compañía General Madrileña de Electricidad.
} 


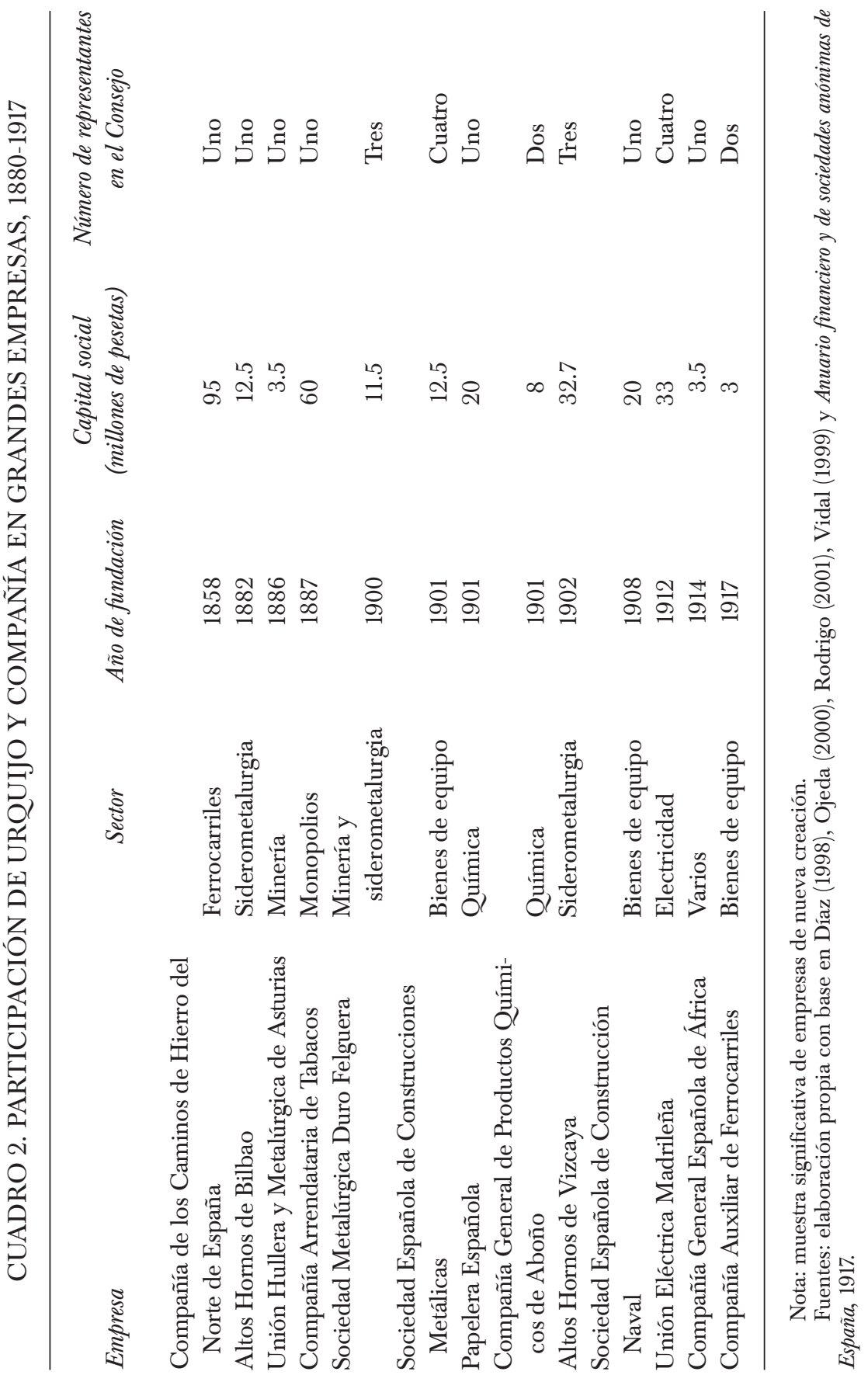


Así pues, el grueso de las participaciones de la Casa Urquijo en empresas industriales se concentró en tres sectores: ferrocarriles, siderometalurgia y electricidad. Se trata de una diversificación relacionada en tanto que existían importantes nexos productivos entre ellos, en particular entre los dos primeros. Por otro lado, estas empresas estaban obligadas a realizar fuertes inversiones en capital fijo y, por consiguiente, tenían una elevada necesidad de financiación a medio y largo plazos (capital en acciones y obligaciones y préstamos). De ahí que, con un mercado de capitales tan poco desarrollado como el español de finales del siglo XIX y principios del Xx, las empresas que contaban con una financiación estable de una entidad bancaria (o de varias) gozasen de cierta ventaja competitiva respecto a las demás.

Para los dueños de estas participaciones, como ocurre con Urquijo, las ventajas fueron varias, por ejemplo la de convertirse en banquero de la firma participada (tesorería, descuento de efectos, depósitos, custodia de títulos, etc.) o la posibilidad de acceder a una información valiosa sobre su funcionamiento y estrategia, susceptible de ser utilizada, entre otras cosas, para orientar la estrategia de las demás empresas participadas, así como para incrementar los flujos comerciales entre ellas bajo la consideración de clientes o proveedores preferentes. Este flujo de información, entre las empresas participadas y los diferentes socios presentes en su accionariado, favoreció la concentración y cartelización de mercados como el siderúrgico (Central Siderúrgica, 1907), así como la mayor capacidad de presión que ejercieron sobre los poderes públicos los empresarios del sector siderometalúrgico a fin de obtener un marco normativo que protegiese a la industria nacional de la competencia extranjera (aranceles protectores de 1891 y 1906 y leyes de fomento de la producción nacional de 1907 y 1917). La labor del segundo marqués de Urquijo, en este aspecto, no fue desdeñable (Díaz, 1998).

\section{FUNDACIÓN DEL BANCO URQUIJO Y EXPANSIÓN DEL GRUPO}

(1918-1936)

Esta etapa, coincidente con el periodo de entreguerras que terminó con el inicio de la guerra civil (1936-1939), tiene como protagonistas a los tres hijos del segundo marqués de Urquijo: Estanislao (tercer marqués de Urquijo), Juan Manuel y Luis Urquijo Ussía; es decir, la tercera generación de la familia. Los tres continuaron la estrategia de fomento de la industria nacional iniciada por su progenitor, lo que dio como resultado un grupo de empresas, participadas y/o controladas, más numeroso, diversificado y fuerte desde el punto de vista financiero. El éxito de esta estrategia obede- 
ce no sólo a los recursos y capacidades acumulados por la Casa Urquijo durante más de medio siglo, sino también a factores coyunturales y de contexto institucional favorables a la misma.

Así, el contexto de la primera guerra mundial (1914-1918), ventajosa para la economía española debido a la neutralidad del país en el conflicto, deparó grandes beneficios en numerosas actividades -la minería del carbón y la siderurgia, entre ellas- y acentuó la tendencia nacionalista de la política económica española durante los años veinte. Un episodio destacable de la misma lo constituye el proceso de rescate (españolización) de títulos públicos (deuda exterior) y privados nominados en francos en manos, sobre todo, de entidades y particulares franceses y belgas. En este rescate se involucró, desde 1916, la Casa Urquijo junto a otras entidades bancarias con la aquiescencia de las autoridades españolas (gobierno y Banco de España). Las otras entidades fueron Banesto y el Banco de Vizcaya, fundamentalmente, con los que el Banco Urquijo (y Paribas) fundó en 1920 el Banco Hispano Francés, domiciliado en París. Esta entidad fue un instrumento al servicio de la estrategia de españolización de títulos hasta su disolución en 1928 (Puig y Torres, 2008, pp. 51-52).

Además del negocio bancario que llevaba implícito, el interés de los hermanos Urquijo Ussía en este proceso estribó en las muchas e importantes empresas controladas por capital francés en las que cabía la posibilidad de entrar a través de la españolización, parcial o total, de su capital, principalmente en los sectores eléctrico, químico y de transportes. Castro (2010) habla de pérdida de posiciones de la banca francesa en España después de la primera guerra mundial (pp. 93-97). Esto ayuda a explicar el nacimiento del Banco Urquijo en 1918 y la posterior creación de varios bancos filiales entre 1918 y 1920 para aumentar la capacidad financiera del grupo (véase cuadro 3).

El Banco Urquijo nació para continuar la actividad y los negocios de Urquijo y Compañía con un capital de 50000000 de pesetas, totalmente desembolsadas en 1921. Casi todo este recurso fue aportado por los tres hermanos Urquijo Ussía, que ejercieron un control absoluto sobre la entidad. Una pequeña participación quedó en manos de sus cuñados, Juan Tomás de Gandarias Durañona y Francisco de Cubas Erice, que eran, a su vez, dos destacados empresarios.

Los bancos filiales, por su parte, los crearon en las regiones donde era más pujante la industrialización (Asturias, País Vasco y Cataluña) para tratar de atraer a los empresarios establecidos en estos territorios con el objetivo doble de tenerlos como socios en la creación de nuevos negocios y gestionar la parte financiera de sus empresas, además de su propio patrimonio personal. El resultado de esta estrategia fue limitado en Asturias, algo mejor en el País Vasco y notable en Cataluña, donde lograron asociar 
CUADRO 3. BANCO URQUIJO Y BANCOS FILIALES, 1921-1935 (EN MILLONES DE PESETAS CORRIENTES)

\begin{tabular}{|c|c|c|c|c|c|c|}
\hline \multirow[b]{2}{*}{ Nombre } & \multirow{2}{*}{$\begin{array}{l}\text { Domicilio } \\
\text { social }\end{array}$} & \multirow{2}{*}{$\begin{array}{c}\text { Año de } \\
\text { fundación }\end{array}$} & \multicolumn{2}{|c|}{ Capital $^{\mathrm{a}}$} & \multicolumn{2}{|c|}{ Inversión ${ }^{\mathrm{b}}$} \\
\hline & & & 1921 & 1935 & 1921 & 1935 \\
\hline Banco Urquijo & Madrid & 1918 & 78.7 & 90.2 & 221.7 & 373 \\
\hline $\begin{array}{l}\text { Banco Minero } \\
\text { e Industrial de } \\
\text { Asturias }\end{array}$ & Gijón & 1918 & 5 & 5.3 & 15.5 & 10 \\
\hline $\begin{array}{c}\text { Banco Urquijo } \\
\text { Vascongado }\end{array}$ & Bilbao & 1918 & 10.5 & 11.8 & $18^{\mathrm{d}}$ & 62.2 \\
\hline $\begin{array}{l}\text { Banco Urquijo } \\
\text { Catalán }\end{array}$ & Barcelona & 1919 & 12.6 & 15 & 38.4 & 86.9 \\
\hline $\begin{array}{l}\text { Banco Urquijo } \\
\text { de Guipúzcoa }\end{array}$ & $\begin{array}{l}\text { San Sebas- } \\
\text { tián }\end{array}$ & 1920 & 10 & 21.8 & $8.8^{\mathrm{d}}$ & 34.3 \\
\hline $\begin{array}{l}\text { Banco del Oeste } \\
\text { de España }\end{array}$ & Salamanca & $1927^{c}$ & & 5.5 & & 50 \\
\hline Total & & & 116.8 & 149.6 & 302.4 & 616.4 \\
\hline
\end{tabular}

Capital desembolsado más reservas; ${ }^{\text {b }}$ cartera más créditos; ${ }^{\text {c }}$ toma de control por parte del Banco Urquijo, ${ }^{\mathrm{d}}$ sólo cartera.

Fuente: elaboración propia con base en Banco Urquijo, Memoria anual, años 1921 y 1935.

a empresarios y a financieros destacados como Damián Mateu, Santiago Trías Rumeu, Ignacio Coll y Luis Alfonso Sedó, con intereses en industrias como la fabricación de automóviles y textiles, entre otras.

Otra consecuencia de esta estrategia fue la mayor capacidad del Banco Urquijo para la gestión y control de las empresas participadas. En su consejo de administración entraron Luis Salazar y Luis Alfonso Sedó, procedentes de los bancos filiales (véase anexo 1). Se unieron a los tres hermanos Urquijo Ussía, que fueron los máximos responsables de la gestión de la entidad y asumieron la representación de sus intereses en un amplio número de empresas. Asimismo, se incorporó a la gestión del Banco Urquijo Valentín Ruiz Senén, un abogado ajeno a la familia propietaria, en quien los hermanos Urquijo Ussía depositaron su confianza. Ruiz Senén actuó como consejero delegado del Banco Urquijo y contribuyó a trazar y ejecutar las líneas maestras de su estrategia durante todo este periodo. No obstante, durante la segunda república (1931-1936), en un clima hostil a la ideología monárquica, que profesaban los propietarios del Banco Urquijo, se incorporó a su gestión a profesionales ajenos a la entidad que tenían una 
imagen más aceptable para los gobernantes republicanos. Tal es el caso de Juan Lladó Sánchez-Blanco, personaje fundamental en el desarrollo del grupo Urquijo durante el periodo franquista.

El cuadro 4 dista mucho de ser un recuento completo del centenar de firmas de diversos sectores en las que la entidad madrileña estaba presente hacia 1930 (Puig y Torres, 2011, anexo 1); no obstante, refleja algunas características destacables de su estrategia de expansión en esta etapa. En primer lugar, sobresale la importancia de las participaciones en empresas eléctricas, un sector que se desarrolló en estos años a partir de la producción hidroeléctrica (Bartolomé, 2007). Dejando aparte a la Compañía Hispano Americana de Electricidad - multinacional sin actividad específica en España, cuya constitución reforzó los vínculos de los bancos españoles con las principales empresas y los bancos europeos del sector eléctrico (Anes, 1999)-, el Banco Urquijo consolidó su presencia en el mercado madrileño con la Eléctrica de Castilla y Saltos del Alberche, reforzando la posición de la Unión Eléctrica Madrileña. También se estableció en Aragón y Cataluña con la Sociedad Productora de Fuerzas Motrices, Energía e Industrias Aragonesas y Fuerzas Hidroeléctricas de Andorra, y en Asturias, con la compañía Eléctrica de Langreo. Además, entró en el capital de Saltos del Duero, que fue la mayor empresa del sector en la década de 1930. Lo hizo en un contexto de rivalidad y cooperación con las empresas del Banco de Vizcaya, Hidroeléctrica Ibérica e Hidroeléctrica Española, que constituían el grupo líder en este sector. Asimismo, participó en la implantación de la industria electroquímica en España a través de Energía e Industrias Aragonesas y de la Sociedad Ibérica del Nitrógeno, empresas que fabricaron, sobre todo, inputs para la producción de abonos nitrogenados.

En segundo lugar, el gran volumen de financiación básica requerido por las empresas hidroeléctricas fue una vía efectiva para la participación del Banco Urquijo en estas, pero también de otros bancos que tenían intereses similares en el sector o que buscaron la expansión de su negocio financiero propiamente dicho. Así cabe entender la presencia de los principales bancos nacionales (Banesto, Hispano Americano, Vizcaya, Bilbao, Santander, etc.) y de otros menos importantes en muchas de las empresas del sector, participadas o no por el Banco Urquijo. Este fenómeno debe enmarcarse en la orientación nacionalista de la política económica española. Esta política favoreció la creación de entidades donde confluyeron la iniciativa privada y el interés público, y la constitución de influyentes grupos de presión capaces de orientar la acción del Estado en su beneficio. Ejemplos de esto son la participación del Banco Urquijo, junto con una amplia representación de bancos y empresarios particulares, en la creación en 1920 del Banco de Crédito Industrial, una 


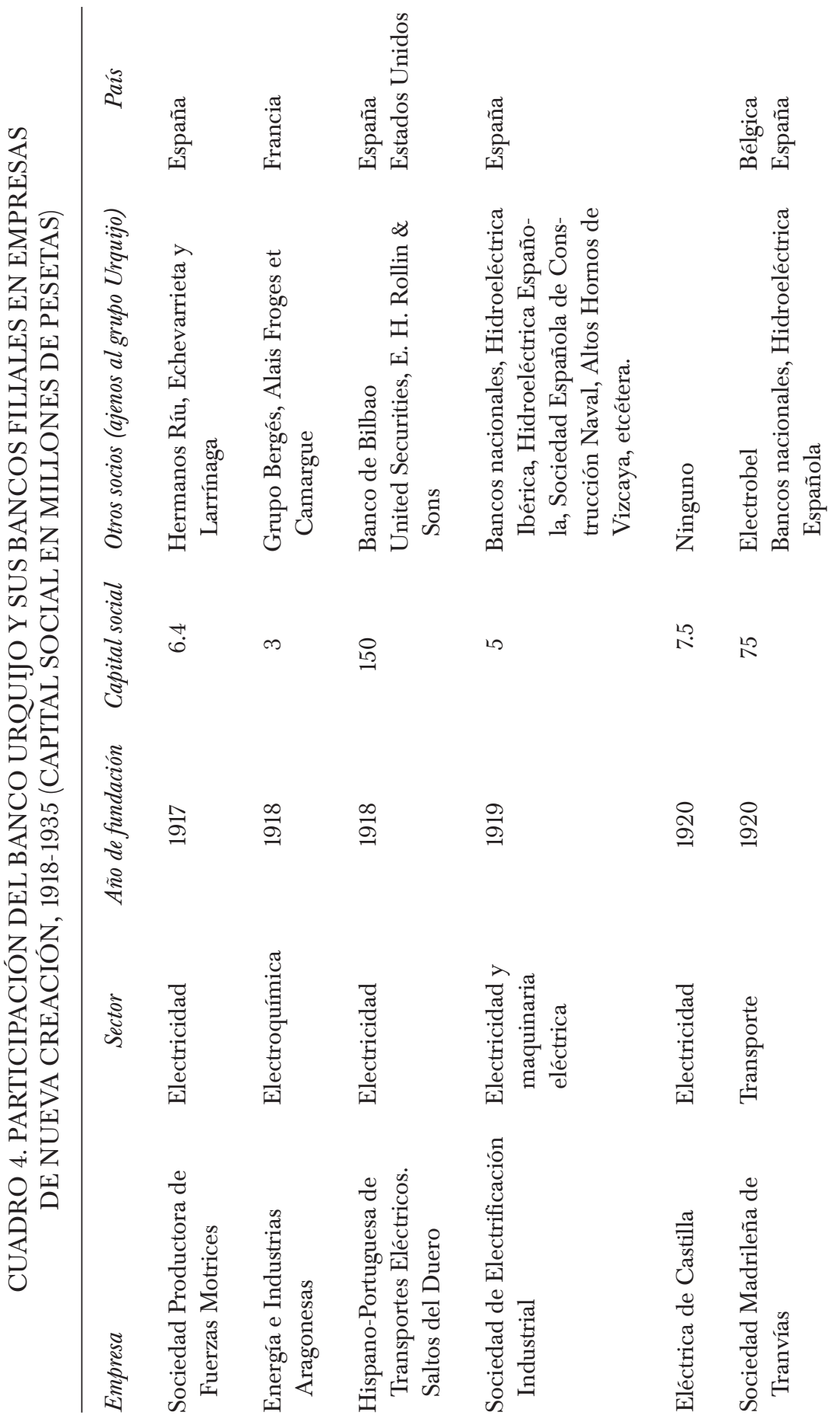




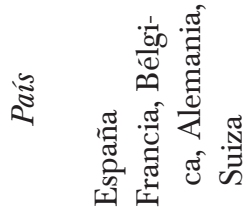

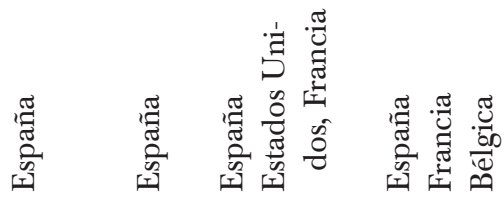

:

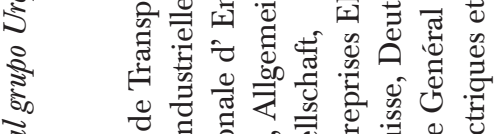

₹

S

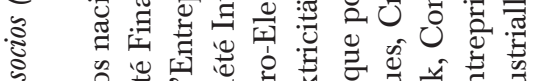

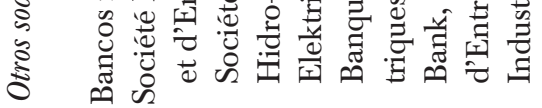

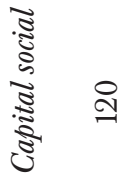

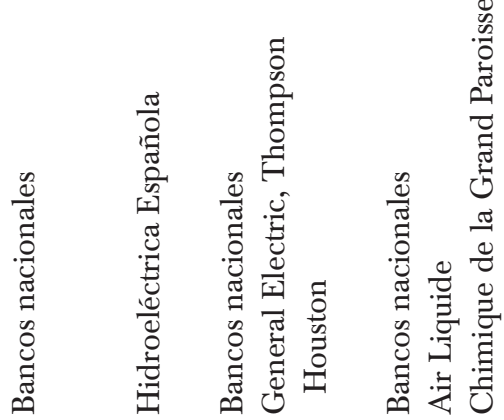

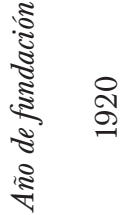

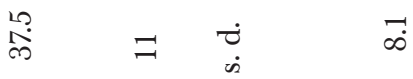

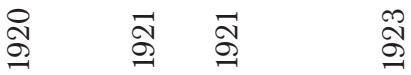

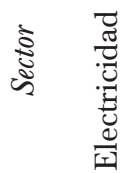

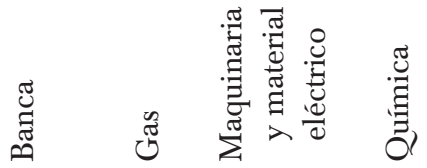
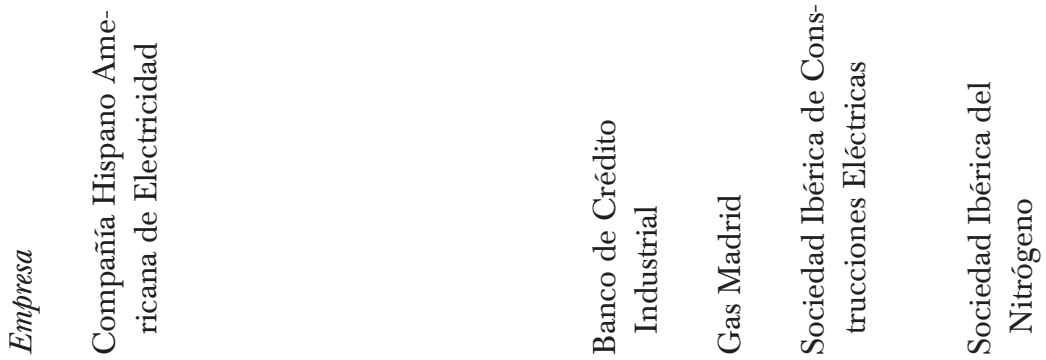


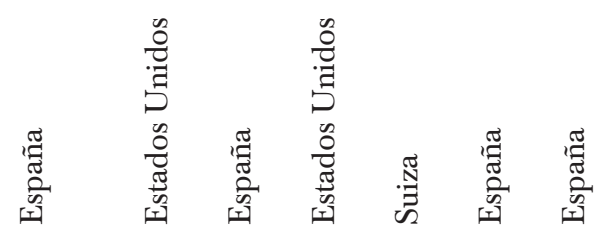

喜

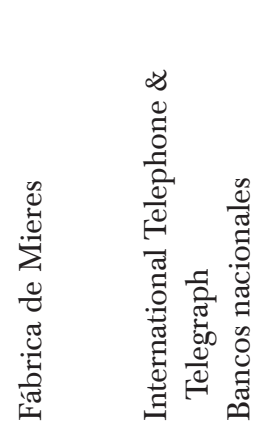

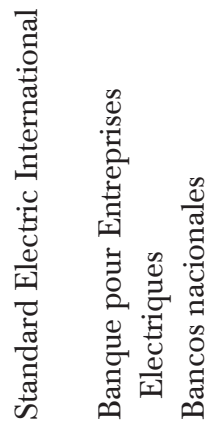

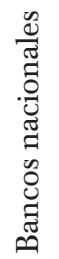

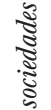

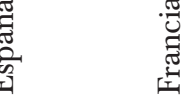

$\frac{8}{2}$

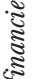

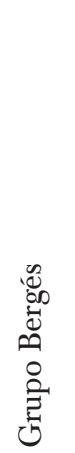

ำ

$\stackrel{\lambda}{\infty}$

㠃

$\therefore \quad$ 응

$\stackrel{2}{9}$

$\circ \quad$

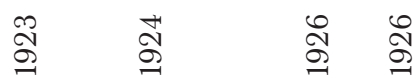

ลิ

ลิ

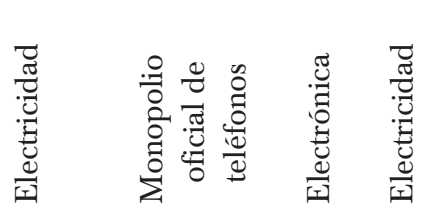

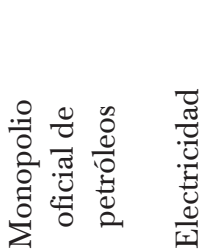

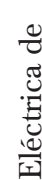

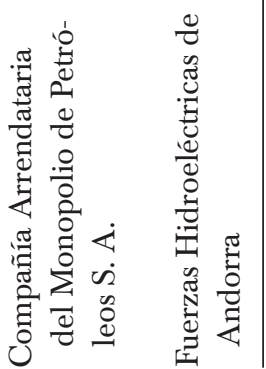

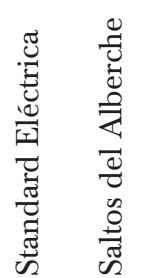

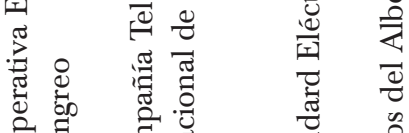

ठำ

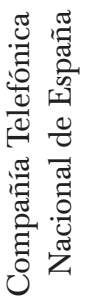

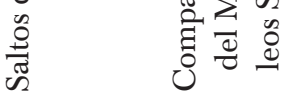

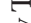

.

高

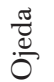

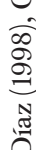

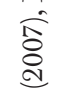

:

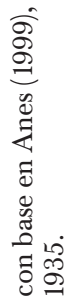

궁을

응

ㅇำ

엉

현

is

궁

㱐 
entidad oficial llamada a ser un pilar básico de la política de fomento de la industria nacional; o su concurso, con el resto de los grandes bancos, en la fundación en 1927 de la Compañía Arrendataria del Monopolio de Petróleos, S. A., la empresa a la que el gobierno le concedió la gestión del monopolio de petróleos. Asimismo, el Banco Urquijo compartió la acción de lobby de los bancos españoles antes y después de la integración de todos ellos en 1921 en el Consejo Superior Bancario, un organismo oficial que tenía, entre otras, la función de asesorar y apoyar la política financiera del gobierno.

Por último, en el cuadro 4 se muestra la presencia de importantes empresas extranjeras en el capital y la gestión de las firmas en las que participaba el Banco Urquijo. Con frecuencia, sobre todo en el sector eléctrico, se trataba de firmas con experiencia inversora y conocimiento del mercado español; otras eran nuevas, como ocurre con la Compañía Telefónica Nacional de España, creada en 1924 con capital y tecnología de la International Telephone \& Telegraph, a la que el gobierno español le concedió la gestión del monopolio de los servicios telefónicos. Como socio de unas y otras, el Banco Urquijo aportó a los negocios compartidos sus capacidades financieras y de gestión, así como su red de contactos con las autoridades gubernamentales. Las empresas extranjeras aportaron, sobre todo, los recursos tecnológicos de la segunda revolución industrial que escaseaban en España.

\section{LA REINVENCIÓN DEL GRUPo URQUiJO DE LA MANO DE JUAN LLADÓ, 1939-1959}

Este periodo se caracteriza por la respuesta que los responsables del Banco Urquijo dieron al nuevo marco institucional impuesto al final de la guerra civil por los gobiernos del nuevo Estado, que era restrictivo para la iniciativa privada, a la política económica extremadamente intervencionista que implantaron, a la creación del Instituto Nacional de Industria en 1941 (competidor directo en muchas industrias) y al aislamiento del exterior al que se vio sujeta la economía española hasta los primeros años de la década de 1950. Todos ellos fueron factores adversos a los intereses del grupo Urquijo, donde Juan Lladó Sánchez-Blanco fue la persona idónea para reorganizarlo y definir la estrategia que lo convirtió en el principal grupo empresarial privado de España en los años sesenta.

Abogado y letrado del Consejo de Estado, Lladó tenía una gran capacidad para las relaciones personales y la búsqueda de acuerdos, contaba con una amplia red de amistades y conocidos. Había entrado en el Banco Urquijo en 1932 para facilitar las relaciones de la entidad con las autoridades 
republicanas. Durante la guerra civil realizó una labor eficaz como salvaguardia del patrimonio y los intereses del Banco Urquijo, que los hermanos Urquijo Ussía supieron valorar otorgándole toda su confianza; de manera que en 1944 se convirtió en consejero delegado de la entidad, una vez que dio solución al grave problema de la financiación del grupo Urquijo.

En efecto, la recuperación de la actividad de las principales empresas participadas requería de suficientes canales de financiación que el Banco Urquijo por sí sólo no estaba en condiciones de aportar. En el periodo anterior a la guerra civil, este problema se resolvió gracias a las facilidades proporcionadas por el Banco de España (descuento de efectos y pignoración de títulos de deuda pública). Pero después de 1939 dicho procedimiento entrañaba serios riesgos, debido al talante intervencionista de las nuevas autoridades. La solución que encontró Lladó, en 1942, formalizada en 1944, fue una alianza estratégica con el Banco Hispano Americano, el principal banco del país; esta alianza fue conocida como pacto de Las Jarillas. De acuerdo con este, ambos bancos reconocieron sus respectivas especializaciones: comercial y de depósito (Banco Hispano Americano) e industrial (Banco Urquijo), y se comprometieron a colaborar concediendo el primero al segundo facilidades financieras y participando en las emisiones de valores industriales y en la concesión de créditos a empresas. El Banco Hispano Americano tomaba una parte del capital del Banco Urquijo (25\%), sindicándola con la que poseía la familia Urquijo (50\%), y absorbía los bancos filiales de este. Hubo un intercambio de consejeros entre las dos entidades y se nombró una comisión mixta para el seguimiento del pacto (Puig y Torres, 2008, pp. 112-113; Tortella y García, 1999). Los efectos de esta alianza y la mejoría experimentada por la economía española en la década de 1950, un periodo inflacionista, impulsaron el crecimiento del balance del Banco Urquijo en todas sus partidas (véase cuadro 5).

Además de la contribución del Banco Hispano Americano, el Banco Urquijo buscó vías complementarias de financiación dentro y fuera de España. En el interior, impulsó la creación de sociedades de cartera y de inversión mobiliaria, como Industria y Navegación, fundada en 1946 con la familia Aznar (véase cuadro 6). En el exterior realizó una labor de diplomacia callada y tenaz ante las empresas y bancos extranjeros con los que mantenía relación desde tiempos antiguos, que dio sus frutos en los años cincuenta, en el contexto de la guerra fría. Así, en 1952 se concretó el primero de una serie de créditos del Eximbank a favor, entre otras, de cuatro empresas del grupo Urquijo: Unión Eléctrica Madrileña, Sociedad Ibérica del Nitrógeno, Unión Española de Explosivos y Explotaciones Potásicas. Después, los pactos hispano-estadunidenses firmados en 1953, y la ayuda técnica y económica asociada a ellos, supusieron un estímulo 
CUADRO 5. PRINCIPALES PARTIDAS DEL BALANCE DEL BANCO

URQUIJO, 1942-1959 (EN MILLONES DE PESETAS CORRIENTES)

\begin{tabular}{lccc}
\hline & 1942 & 1950 & 1959 \\
& & & \\
Cartera de efectos & 82.5 & 347.1 & 2015.4 \\
Cartera de fondos públicos & 153.6 & 359.1 & 1356.8 \\
Cartera de valores industriales & 182.2 & 701.6 & 2110.8 \\
Créditos & 119 & 292.4 & 724.2 \\
Deudores por avales y otros & s. d. & 180 & 1244.1 \\
Capital desembolsado & 68.8 & 150 & 330 \\
Reservas $_{\text {Depósitos }}^{\mathrm{a}}$ & 35.7 & 150 & 650 \\
& 428 & 1230.7 & 4220.5 \\
\hline
\end{tabular}

a A la vista, a plazo, en moneda extranjera.

Fuente: Banco Urquijo, Memoria anual, años 1942, 1950 y 1959.

adicional para la creación de empresas en el sector de la ingeniería civil (Estudios y Proyectos Técnicos Industriales) y la construcción de obra pública (Técnicas Especiales de Construcción). En 1949 firmó un protocolo en Francia con Paribas, y en 1953 obtuvo de la banca francesa, liderada por esta entidad, un crédito de 15000 millones de francos del que se beneficiaron, sobre todo, Duro Felguera, La Naval y la Compañía Auxiliar de Ferrocarriles. Y en Alemania, en 1958, el Banco Urquijo y el Deutsche Bank ratificaron un acuerdo que, entre otras cosas, abrió la puerta a la ayuda económica y a la inversión privada procedente de este país (Banco Urquijo, Memorias anuales 1950-1959; Puig y Torres, 2008, pp. 137-145).

La alianza con el Banco Hispano Americano trajo consigo consecuencias de orden interno en el Banco Urquijo. En desacuerdo con ella, Luis Urquijo Ussía, marqués de Amurrio, renunció a su puesto en el consejo de administración en 1942 y vendió su participación en el capital. Su conducta fue seguida por Valentín Ruiz Senén, consejero delegado entre 1918 y 1942. En los años siguientes, Lladó gestionó con éxito el cambio generacional que supuso el paso de la tercera a la cuarta generación de la familia Urquijo. El marqués de Urquijo falleció en 1948 y su hermano Juan Manuel en 1956. Previamente habían muerto sus cuñados Francisco de Cubas Erice, en 1937, y Juan Tomás de Gandarias Durañona, en 1940. La cuarta generación ocupó sus vacantes en el consejo: Luis Urquijo Landecho, marqués de Bolarque, Francisco Urquijo de Federico, Felipe de Cubas Urquijo y Pedro Pascual de Gandarias Urquijo (véase anexo 1). Además de los representantes de la familia fundadora, el consejo era cada 
vez más numeroso, ya que se incorporaron no sólo los representantes del Banco Hispano Americano, Luis Usera e Ignacio Herrero Garralda, sino también, en 1939, los consejeros de los bancos filiales que habían destacado más en su gestión o podían reportar más utilidad al Banco Urquijo (Alberto Paquet, César Balmaseda, Santiago Trías Rumeu, Enrique Urbina y José Félix de Lequerica), así como los técnicos más competentes y experimentados en la gestión de algunas de las empresas del grupo Urquijo: los ingenieros de minas Antonio Lucio-Villegas (Duro Felguera) y José Cabrera (Unión Eléctrica Madrileña).

Asimismo, en estos años algunos de los nuevos socios del Banco Urquijo entraron en el consejo. Es el caso de la familia Aznar, propietaria del grupo Aznar (Bilbao), que en 1945 firmó un acuerdo de sindicación de acciones con la entidad madrileña (Valdaliso, 2006). Con la familia Bertrand Mata, propietaria de Catalana de Gas y Electricidad (Barcelona), el Banco Urquijo estableció una alianza estratégica para crear conjuntamente Hidroeléctrica de Cataluña en 1946, que fue el primer paso para ordenar el desarrollo de los intereses hidroeléctricos que tenía el banco madrileño en la zona de los Pirineos. En la década de 1960 se incorporó al consejo Javier Benjumea, un dinámico empresario sevillano que estrechó relaciones con el Banco Urquijo durante el proceso de nacionalización del capital británico en las minas de Río Tinto; Benjumea se convirtió en un socio habitual del banco en las iniciativas que se llevaron a cabo con capital americano (Westinghouse, Minnesota Mining and Manufacturing Company, Lummus, etc.) (Hoyo y Escriña, 2003); por último, Pablo Díez, empresario español afincado en México, con el que el Banco Urquijo creó Perlofil para la fabricación de fibras sintéticas (véase cuadro 6).

La gestión de Lladó sobresale también por haber potenciado los Servicios Técnicos y de Estudios, uno de los instrumentos que más contribuyeron al desarrollo y fortalecimiento del grupo Urquijo a partir de la década de 1940, y que le dieron al Banco Urquijo, además de prestigio, la capacidad específica (técnica) para ejecutar proyectos; esta es una característica distintiva de los grupos empresariales de acuerdo con Kock y Guillén (2001), y Amsden y Hikino (1994). Su origen era una comisión de estudios creada en 1939 para conocer las posibilidades de desarrollo de los negocios del grupo Urquijo. Lladó se puso al frente de la misma en 1942 y la disolvió en 1944, después de haber realizado "una labor estadística y analítica de valor inapreciable para el control directivo de las empresas" (Puig y Torres, 2008, p. 107). De ella surgieron los Servicios Técnicos, por un lado, y el Servicio de Estudios, por otro, que constituyeron, en conjunto, el núcleo del capital humano de más valor del grupo Urquijo.

Dirigidos por ingenieros con experiencia, los Servicios Técnicos se organizaron en secciones especializadas y su labor principal consistió en 


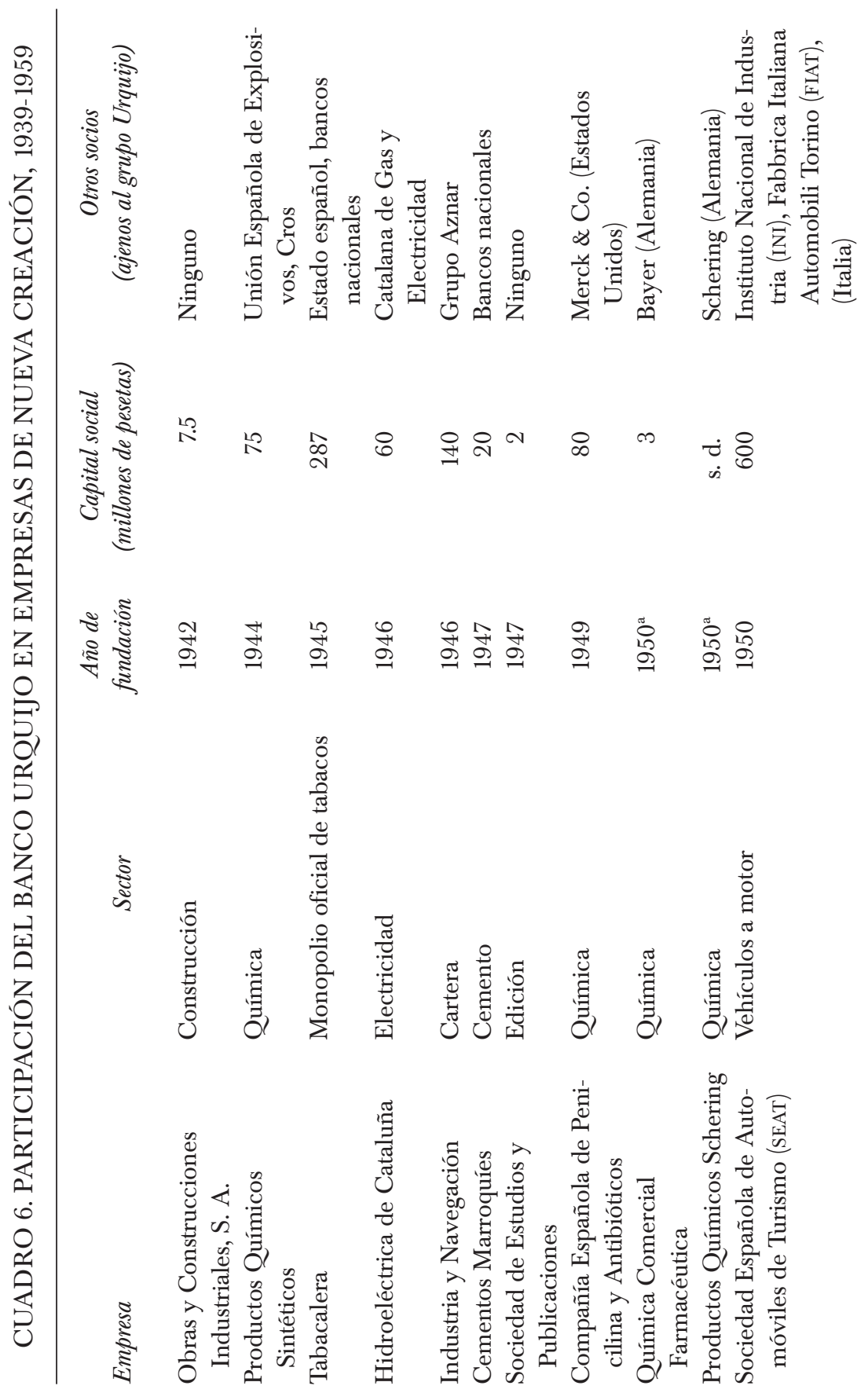




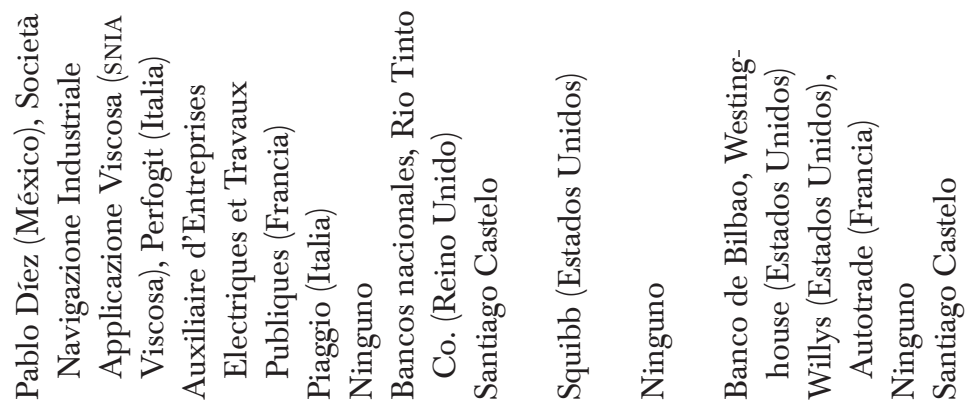

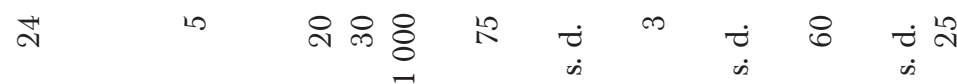

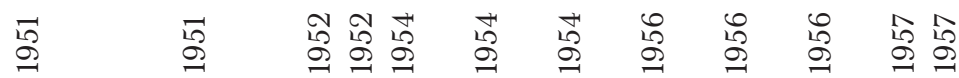
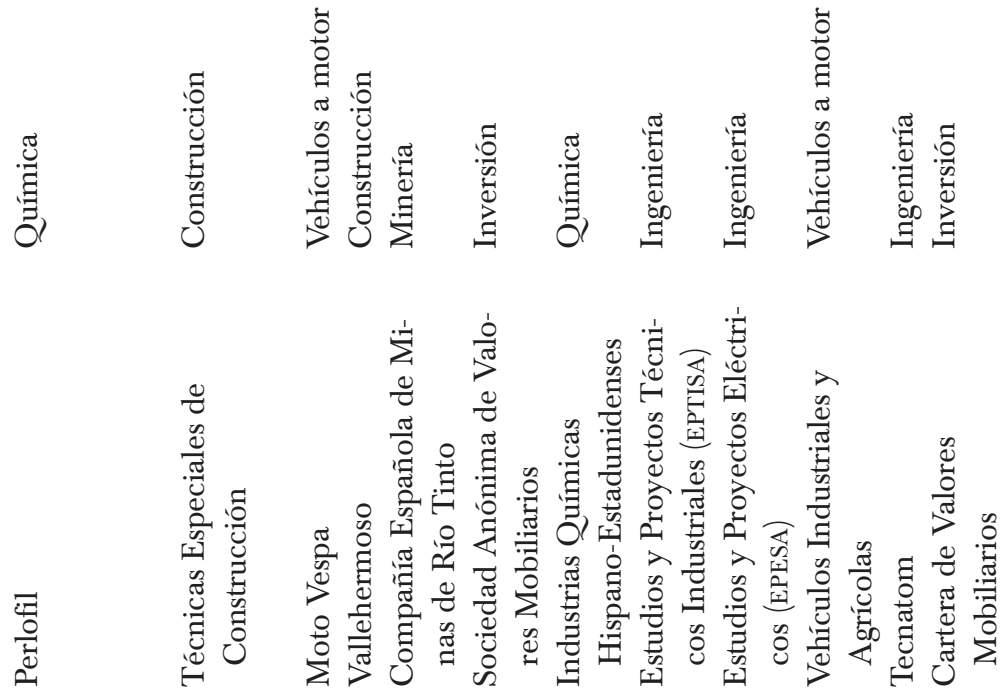


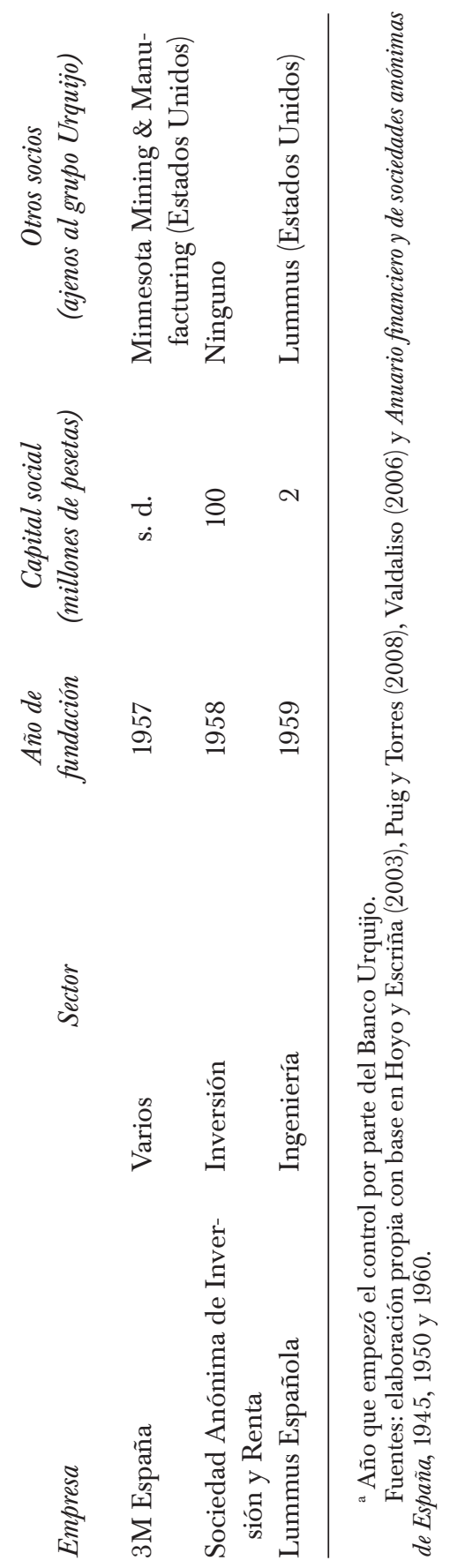


asesorar y orientar técnicamente a las empresas en cada sector, así como en estudiar las posibilidades de nuevos negocios y la ampliación de los existentes. La mayoría de sus miembros pasaron poco a poco a formar parte de los cuadros directivos de estas empresas. Los principales fueron los Servicios Eléctricos, los Siderometalúrgicos y los Químicos, coincidiendo con los sectores que concentraron el mayor volumen de recursos y de iniciativas dentro del grupo Urquijo (véase cuadro 6). Fueron también la cantera de la que surgieron las primeras empresas de ingeniería: Estudios y Proyectos Técnicos Industriales (ingeniería civil), Tecnatom (ingeniería nuclear) y Lummus Española (ingeniería petroquímica).

El Servicio de Estudios, por su parte, tuvo como misión la inspección y control de las empresas filiales, el control de las sociedades participadas y el estudio de las empresas en las que el Banco Urquijo no participaba (la competencia). Se encargó también de hacer un seguimiento de la economía española y extranjera, de elaborar estadísticas, estudios e informes periódicos sobre el desarrollo o las perspectivas de crecimiento de diversos sectores productivos, sobre instituciones financieras, inversiones extranjeras, etc. Fue responsable de la publicación de un informe anual titulado Economía Española, que empezó a elaborarse en 1945 bajo la dirección de Julio Tejero, catedrático de economía política y amigo de Lladó, que desde 1942 dirigió también un proyecto paralelo, la revista de economía Moneda y Crédito.

Por último, el gran reto de Lladó en las décadas de 1940 y 1950 fue dirigir al grupo Urquijo por los vericuetos del fuerte intervencionismo del Estado y de la orientación estatizadora defendida por algunos de sus principales dirigentes. Fue una labor complicada y compleja, porque los intereses del grupo eran heterogéneos y porque la administración franquista no fue un ente monolítico en la interpretación y aplicación de la política de intervención. El rico capital de relaciones personales y contactos que poseía el Banco Urquijo resultó ser un eficaz instrumento al respecto, dentro de una estrategia de adaptación que evitó por todos los medios la confrontación con el sector público y buscó la transacción y el acuerdo. Hubo veces en que sus intereses resultaron favorecidos, como ocurrió, sobre todo, en la adjudicación que el Estado hizo de las filiales de empresas alemanas expropiadas al final de la segunda guerra mundial, lo que le permitió fortalecer su presencia en el sector químico-farmacéutico con firmas como Química Comercial Farmacéutica, Productos Químicos Schering y la Compañía Española de Penicilina y Antibióticos (véase cuadro 6). Pero hubo también ocasiones en que sus intereses salieron perjudicados. Así ocurrió con la creación de Empresa Nacional Siderúrgica S. A. por el Instituto Nacional de Industria en 1950, lo que supuso la entrada en el sector siderúrgico de un poderoso com- 
petidor para Duro Felguera y Altos Hornos de Vizcaya. Otro caso es el de la Sociedad Española de Automóviles de Turismo (SEAT), que ilustra cómo la actuación del Ministerio de Industria y del Instituto Nacional de Industria frustraron, en 1940, un proyecto de fabricación de automóviles por iniciativa del Banco Urquijo, y cómo hasta 1950 no se concretó otro nuevo, el de SEAT, en el que participaron ambas entidades con el apoyo técnico y financiero de la Fabbrica Italiana Automobili Torino (FIAT) (San Román, 1999).

\section{LA EDAD DORADA DEL GRUPO URQUIJO, 1960-1974}

El cambio en la orientación de la política económica española (Plan de Estabilización de 1959) impulsó un fuerte crecimiento y el país se industrializó aceleradamente entre 1960 y 1974. El mayor protagonismo del mercado y la apertura al exterior liberaron importantes recursos internos y facilitaron la llegada de inversiones extranjeras. Aprovechando las ventajas de la reorganización que había experimentado en las décadas de 1940 y 1950, el Banco Urquijo estuvo en condiciones de ejercer sus funciones de banco industrial como nunca lo había hecho hasta entonces. De forma que experimentó también un crecimiento espectacular y aumentó el tamaño de su grupo de empresas presentes a su vez en un amplio abanico de sectores e industrias (véanse cuadros 7 y 8), compuesto hacia 1970 por un número cercano a los tres centenares de firmas (Puig y Torres, 2011, anexo 3).

La cartera de valores industriales continuó como principal instrumento de promoción de nuevas empresas, mientras la financiación a corto y largo plazos de las ya existentes -las de mayor tamaño, por lo general- se canalizó a través de la cartera de efectos (redescontables en el Banco de España), de los créditos y de los avales y garantías de créditos concedidos por terceros (principalmente, banca pública nacional y bancos extranjeros). Por el lado del pasivo, los depósitos, los recursos propios (capital y reservas) y los bonos de caja, activos financieros de renta fija emitidos a un plazo no inferior a dos años, constituyeron las principales fuentes de financiación del Banco Urquijo. La capacidad para emitir estos bonos la otorgó la Ley de Ordenación del Crédito y la Banca del 14 de abril de 1962 (Martínez, 1971), en vigor hasta 1974 y que estableció a su vez una especialización bancaria al permitir la constitución de bancos industriales y de negocios para promover la creación de empresas y la financiación a medio y largo plazos de la industria. Casi todas las emisiones de bonos de caja que hizo el Banco Urquijo fueron convertibles en acciones suyas, lo que le permitió elevar sus recursos 


\section{CUADRO 7. PRINCIPALES PARTIDAS DEL BALANCE DEL BANCO URQUIJO, 1965-1974 (EN MILLONES DE PESETAS CORRIENTES)}

\begin{tabular}{lcrr}
\hline & 1965 & 1970 & 1974 \\
& & & \\
Cartera de efectos & 6285.5 & 18117.4 & 25315.7 \\
Cartera de fondos públicos & 1400.9 & 1297.1 & 1466.5 \\
Cartera de valores industriales & 3561 & 5623.8 & 12811.7 \\
Créditos & 1309.9 & 7234.5 & 38973.4 \\
Deudores por avales y otros & 7130 & 9321.6 & 14872.3 \\
Capital desembolsado & 577.5 & 1717.2 & 4860.7 \\
Reservas & 1134 & 5102.2 & 11803.2 \\
Depósitos & 9488.2 & 19117.6 & 51413.8 \\
Bonos de caja $^{\text {a }}$ & 1500 & 5607.8 & 10072.1 \\
\hline
\end{tabular}

${ }^{a}$ A la vista, a plazo, en moneda extranjera, certificados de depósito.

Fuente: Banco Urquijo, Memoria anual, años 1965, 1970 y 1974.

propios, en particular la parte correspondiente a reservas. La operativa de los bonos convertibles la adoptó del Credit Suisse (Suiza), entidad con la que constituyó en 1966, junto con Paribas (Francia), Henry Schroder (Gran Bretaña) y otros bancos europeos, un comité internacional para colocar valores españoles en los mercados de capital europeos (Puig y Torres, 2008, p. 187). Para 1970, alrededor de 10\% del capital del Banco Urquijo estaba en manos de no residentes.

El Banco Urquijo aprovechó también las ventajas fiscales que otorgó la Ley de 1962 a la creación de sociedades y fondos de inversión mobiliaria para ampliar su potencial financiero. Entre 1965 y 1966 constituyó dos sociedades gestoras, Gesfondo y Gestinver, que en 1974 gestionaban siete fondos de inversión mobiliaria y un volumen de recursos equivalente a 30\% de todos los fondos en España. En este año, dos nuevas gestoras, Geseco y Servicios Financieros, lanzaron al mercado nueve sociedades de inversión mobiliaria más (Banco Urquijo, Memoria anual, año 1974). La inversión en este tipo de sociedades llegó a ser la segunda en importancia en la cartera de valores del Banco Urquijo (véase cuadro 8).

Con un personal cada vez más profesionalizado, además de un prestigioso y eficaz Servicio de Estudios, la actividad y experiencia financiera del Banco Urquijo aumentó en operaciones bursátiles, asesoramiento de inversiones, comercialización de activos financieros, financiamiento del comercio exterior, dirección de operaciones sindicadas de crédito y de emisiones de bonos, de manera que, desde los primeros años de la década 
CUADRO 8. PORCENTAJE DE DISTRIBUCIÓN SECTORIAL DE LA CARTERA DE VALORES INDUSTRIALES DEL BANCO URQUIJO, 1967-1974

\begin{tabular}{lcc}
\hline Sectores & 1967 & 1974 \\
& & \\
Electricidad y gas & 9.9 & 9.2 \\
Industrias del automóvil & 8.8 & 3.4 \\
Inmobiliarias & 8.4 & 6.6 \\
Químicas & 8.3 & 16.3 \\
Industrias de la construcción & 8.1 & 8.1 \\
Bancos y seguros & 8.1 & 6.2 \\
Sociedades de inversión mobiliaria & 7.9 & 13.4 \\
Fibras sintéticas y plásticos & 6.4 & 1.8 \\
Minería & 5.4 & 4.3 \\
Metalúrgicas transformadoras & 4.8 & 1.8 \\
Industrias de material eléctrico y electrónico & 4.5 & 1.8 \\
Farmacéuticas & 3.3 & 0.5 \\
Alimentación y agrícolas & 2.9 & 2.9 \\
Siderúrgicas & 2.7 & 2.1 \\
Monopolios del Estado & 2 & 2.5 \\
Valores extranjeros & 2 & 5.3 \\
Ingeniería, estudios y financieras & 1.7 & - \\
Comerciales y distribución & 1.6 & 3.3 \\
Transportes & 0.8 & 4.8 \\
Valores industriales de renta fija & 1.3 & - \\
Varios & 1.1 & 2 \\
Cuero y caucho & - & 2.4 \\
Hogar y oficina & - & 1.3 \\
\hline & & \\
\hline
\end{tabular}

Fuente: elaboración propia con base en Banco Urquijo, Memoria anual, años 1967 y 1974.

de 1970, pudo ofrecer nuevas capacidades como banco de inversión -tanto para terceros como para las propias empresas del grupo Urquijo- en un nivel cada vez más parecido a sus tradicionales capacidades como banco de promoción industrial. Sus vínculos con bancos extranjeros y su creciente proyección internacional fueron determinantes al respecto. En 1968 entró en el capital del Banco Continental de la República Argentina y del Banco de Bogotá, Colombia; en 1972 constituyó en Suiza, con el Credit Suisse, la Sociedad Urquijo Finanz A. G.; en 1973 fundó en solitario en Londres el Banco Urquijo Limited, que recibió la autorización del Banco de Inglate- 
rra para operar como merchant bank, y en 1974 abrió una agencia en Nueva York (Banco Urquijo, Memoria anual, años 1972, 1973 y 1974).

Estas mayores capacidades financieras del Banco Urquijo no eran ajenas a la expansión de su grupo de empresas y a las fuertes necesidades de financiación que experimentaron todas ellas, especialmente las más grandes, cuyo crecimiento y reorganización (fusiones, sobre todo) exigieron inversiones de gran cuantía. Asimismo, debe tenerse en cuenta que la implantación de los planes de desarrollo en 1964, por parte del gobierno español, estableció un nuevo marco de intervención del sector público en la industrialización del país más favorable a la colaboración con la iniciativa privada, circunstancia que el Banco Urquijo aprovechó tanto como pudo gracias, en parte, a sus buenas relaciones con los ministros tecnócratas. Se apoyó en los incentivos fiscales y financieros que ofrecían los planes para crear nuevas empresas, y buscó acuerdos con los responsables gubernamentales para dar solución a los problemas de las firmas (públicas y privadas) que operaban en sectores básicos como el siderometalúrgico, la construcción naval, la electricidad, etc., donde el grupo Urquijo tenía una presencia considerable.

La transformación de Duro Felguera es un buen ejemplo de esto último. En 1961 traspasó su actividad siderúrgica, junto con la de otras dos firmas asturianas del sector, a Unión de Siderúrgicas Asturianas S. A. (UNINSA), una empresa nueva que recibió asistencia técnica de la alemana Krupp y, en 1966, ayudas públicas procedentes de la acción concertada en el sector siderúrgico; además, en 1973 se integró con la empresa pública Empresa Nacional Siderúrgica S. A. (EnsidesA). Paralelamente, en 1967 sus minas de carbón se unieron a las de otras firmas privadas asturianas para formar Hulleras del Norte S. A. (HunOSA), empresa creada por el Instituto Nacional de Industria. Liberada así de dos actividades maduras que lastraban su competitividad, Duro Felguera pudo reorientar su estrategia hacia la fabricación de bienes de equipo desde el comienzo de la década de 1970 (Ojeda, 2000). Un proceso parecido tuvo lugar en el sector de la construcción naval, donde el Banco Urquijo tenía importantes intereses, entre estos, La Naval y Euskalduna, razón por la que fue muy activo en las gestiones que llevaron a la fusión de ambas empresas con Astilleros de Cádiz, operación que en 1969 dio lugar a Astilleros Españoles, donde el Instituto Nacional de Industria puso la mitad del capital (Houpt y OrtizVillajos, 2002; Martín y Comín, 1991).

El grupo Urquijo fue también protagonista del crecimiento y las transformaciones que experimentaron otros sectores básicos, como el químico y el eléctrico. En el primero, afianzó su posición de liderazgo en 1969 al constituirse Explosivos Río Tinto como resultado de la fusión de la Unión Española de Explosivos y la Compañía Española de Minas de Río Tinto. 
Hacia 1974 esta empresa era un gigante a escala nacional que contaba con medio centenar de filiales especializadas y recibía el apoyo técnico y financiero de grandes firmas internacionales (Du Pont de Nemours, Progil, Gulf Oil, Shell, Hoechst, etc.) (Explosivos Río Tinto, Memoria anual, año 1974). En el segundo, destaca la introducción de la energía nuclear como fuente de generación de electricidad. La iniciativa correspondió a Unión Eléctrica en la zona centro y a Hidroeléctrica de Cataluña en la región catalana, contando en ambos casos con socios nacionales y extranjeros (Westinghouse, Electricité de France). Catalana de Gas, por su parte, promovió la introducción del gas natural en España con la creación en 1965 de su filial Gas Natural. También en este sector, la promoción de nuevas empresas ya no fue tanto iniciativa del Banco Urquijo como de las sociedades de cabecera citadas, que fueron conformando así grupos industriales específicos. La asociación activa con grandes corporaciones multinacionales había sido históricamente, y lo seguía siendo para la década de 1970, uno de los puntos fuertes de la estrategia del Banco Urquijo como banco industrial (Lladó, 1972).

Otros sectores donde el grupo Urquijo ya estaba bien implantado con anterioridad, como el del cemento, la construcción y la actividad inmobiliaria, experimentaron un fuerte crecimiento entre 1960 y 1974 (véase cuadro 8). Asimismo, el grupo Urquijo amplió su diversificación con una mayor presencia en sectores en los que había penetrado poco hasta entonces o en otros nuevos. Entre los primeros, están la industria agroalimentaria y los transportes marítimos; entre los segundos, deben mencionarse el comercio y la distribución. La diversificación fue también geográfica, tratando de aumentar su presencia en aquellas regiones, como Andalucía o Levante, donde tradicionalmente había sido menor; en 1974 el Banco Urquijo contaba con sucursales en Gijón, Barcelona, Bilbao, Zaragoza, Valencia y Sevilla, la mayoría de las cuales se había abierto en los quince años anteriores (Banco Urquijo, Memoria anual, año 1974). Aunque a ello contribuyó, en parte, la localización industrial inducida por los planes de desarrollo, deben tenerse en cuenta al respecto los numerosos estudios de localización y regionalización de las inversiones que elaboraron los Servicios de Estudios del Banco Urquijo, tanto el de Madrid como el de Barcelona, creado en 1962, y el de Sevilla, que comenzó a funcionar en 1965.

La magnitud de todos estos cambios tuvo consecuencias en la estructura de la propiedad del Banco Urquijo, en su organización interna y en alguna de sus principales señas de identidad. De ser un banco familiar con pocos accionistas -unos 500 hacia 1959 - y la propiedad muy concentrada en la familia Urquijo y en la participación del Banco Hispano Americano, el Banco Urquijo pasó a tener más de 40000 accionistas para 1974 y una propiedad muy diluida. De acuerdo con Juan Lladó Fernández-Urrutia, 
directivo del Banco Urquijo entre 1960 y 1973, si se excluye la participación del Banco Hispano Americano (12.5\%) y la del conjunto de ramas de la familia Urquijo (10\%), no había ningún accionista con una participación superior a 2 por ciento. ${ }^{7}$

Por su parte, el personal (empleados, técnicos, gestores, etc.) aumentó notablemente, y la organización interna, además de profesionalizarse, tendió a burocratizarse, desdibujándose algunos de los rasgos hasta entonces dominantes (confianza, fidelidad y afecto), propios de un banco pequeño y familiar. A esto se unió un amplio cambio generacional en el consejo y en la alta dirección el Banco Urquijo, que ya no fue posible gestionar con la eficacia con la que este trascendental asunto se había resuelto en ocasiones anteriores. Todo ello agrietó el consenso sobre la estrategia a seguir en un momento de incertidumbre sobre el alcance de la crisis económica internacional que acababa de iniciarse y de los cambios en la regulación bancaria (fin de la especialización bancaria de 1962).

El nuevo cambio generacional (paso de la cuarta a la quinta generación de la familia Urquijo) afectó a los principales protagonistas de la historia del Banco Urquijo desde el final de la guerra civil: Luis Urquijo Landecho, marqués de Bolarque, representante de la rama principal de la familia propietaria, y Juan Lladó, el consejero delegado artífice de la transformación del grupo Urquijo a partir de 1942. La excelente relación que ambos mantuvieron constituyó un firme pilar para el desarrollo del Banco Urquijo y de su grupo de empresas, pero no logró evitar las tensiones que se produjeron entre 1973 y 1974 y que provocaron la renuncia del marqués de Bolarque a la presidencia del Banco Urquijo, que fue ocupada por Lladó, y la de este al puesto de consejero delegado (véase anexo 1). Las responsabilidades ejecutivas pasaron al nuevo director general, Jaime Carvajal Urquijo, nieto de Estanislao Urquijo Ussía, uno de los tres fundadores del Banco Urquijo.

En paralelo al proceso de cambio generacional, se negoció con el Banco Hispano Americano la actualización de la alianza de 1944. Tampoco esto resultó fácil, a pesar de que Luis Usera, amigo de Lladó, ostentaba la presidencia de esta entidad desde 1968. Fracasó la opción de fusionar ambas entidades, propuesta por Lladó, y se firmó un acuerdo general en junio de 1973 que pretendía desarrollar las complementariedades de ambos bancos (Banco Urquijo, Memoria anual, año 1973). Aun siendo un acuerdo de mínimos, lo más difícil, sin embargo, fue aplicarlo después y conseguir una eficaz coordinación de los equipos y los medios con que

${ }^{7}$ Juan Lladó Fernández-Urrutia. (22 de diciembre de 2010). Entrevista realizada por Núria Puig Raposo y Eugenio Torres Villanueva. Madrid, España. 
contaban uno y otro, cosa que se consiguió de manera limitada (Puig y Torres, 2008, pp. 210-211).

\section{EL FIN DE UN BANCO INDUSTRIAL, 1975-1982}

Lladó fue presidente de honor hasta su muerte en 1982, y Jaime Carvajal se afianzó al frente del Banco Urquijo al alcanzar la presidencia en 1978. Así culminó un cambio generacional que tuvo como trasfondo un ambiente de crisis e incertidumbre: crisis económica mundial, colapso de la industria tradicional española, fin de los privilegios de la banca industrial y un gran número de interrogantes asociados al cambio político y socioeconómico en España (transición a la democracia). Carvajal representaba a una generación de ejecutivos formados en las oficinas centrales de los socios internacionales del Banco Urquijo (J. P. Morgan, Paribas, Lehman Brothers o Schroder) con un claro perfil financiero. Su apuesta, coherente con su propia trayectoria y con una nueva regulación bancaria que aumentaba la competencia en el sector, consistió en intensificar la actividad del Banco Urquijo como banco de negocios al por mayor, en la que ya había acumulado experiencia desde la década de 1960, y en reducir la cartera industrial concentrándola en los sectores más competitivos.

El Banco Urquijo abrió sucursales en España para captar clientela y depósitos en competencia con los bancos comerciales, y agencias o representaciones en el extranjero: Montreal, Fránkfort, Teherán, Ámsterdam, Abu Dhabi, París, Hong Kong, Río de Janeiro, Islas Caimán y Singapur, México, Brasil y Chile (Banco Urquijo, Memoria anual, años 1975-1982). ${ }^{8} \mathrm{La}$ actividad más importante en el exterior fue la desarrollada por las oficinas de Nueva York y Singapur, además de la filial de Londres. Ambas oficinas concedían créditos a compañías estadunidenses y asiáticas, y lo hacían con un elevado riesgo porque el Banco Urquijo tenía relativamente poca experiencia y conocimiento de los mercados de crédito asiáticos, según las palabras de José María Loizaga Viguri, directivo de esta entidad en 1983 y 1984. ${ }^{9}$ De cualquier forma, la internacionalización del Banco Urquijo fue lo más espectacular de estos años y contribuyó a compensar los menores rendimientos del negocio bancario y la cartera industrial en España.

Hasta 1978, la gestión de la cartera industrial, que en 1974 estaba formada por participaciones en más de 250 empresas, muchas con problemas y casi todas afectadas por la crisis industrial de una u otra forma, se rigió por

\footnotetext{
${ }^{8}$ De las seis sucursales con que contaba en España en 1974 pasó a tener 54 en 1982.

${ }^{9}$ José María Loizaga Viguri. (16 de junio de 2008). Entrevista realizada por Eugenio Torres Villanueva. Madrid, España.
} 
el principio de rotación: desinvertir en las empresas maduras (cotizadas, ${ }^{10}$ poco competitivas y con plantillas abultadas y potencialmente conflictivas) e invertir en las jóvenes (no cotizadas, con personal altamente cualificado e internacionalizadas o con posibilidades de salir al exterior). Pero al llegar Jaime Carvajal a la presidencia se redefinió esta estrategia intensificando la reducción de las participaciones en sociedades del sector industrial. El resultado fue una cartera adelgazada pero con títulos todavía de más de un centenar de firmas (Banco Urquijo, Memoria anual, años 1978 y 1979).

Desde 1979, el impacto de la segunda crisis del petróleo agudizó las dificultades de la industria española y los desequilibrios macroeconómicos del país. En el ejercicio de 1980 la cuenta de resultados del Banco Urquijo registró pérdidas por primera vez. Los problemas, latentes durante dos años, afloraron en el verano de 1982. Aparentemente, el desencadenante fue la venta de Galerías Preciados a Ruiz Mateos S. A. (RumASA) (Toboso, 2000, pp. 372-375), que al generar grandes pérdidas para el Banco Urquijo provocó una inspección del Banco de España, el supervisor bancario. Pero también ha de tenerse en cuenta la crisis de algunas otras empresas importantes (Explosivos Río Tinto, Aluminio Español y Torras Hostench), el deterioro de la posición del Banco Urquijo en los mercados exteriores por la crisis de algunos países fuertemente endeudados (México, Argentina e Indonesia) y la caída de la bolsa. Todo esto contribuyó al debilitamiento de su situación patrimonial, como puso de relieve el informe de auditoría de Arthur Andersen a las cuentas del ejercicio de 1981, de manera que se quedó sin fondos propios suficientes para afrontar su saneamiento (Banco Urquijo, Memoria anual, años 1980-1982; Puig y Torres, 2008, pp. 224-226).

Finalmente, el Banco Urquijo fue rescatado pero no de la forma en que se había hecho con los demás bancos industriales en crisis, es decir, mediante el control de estos por el Fondo de Garantía de Depósitos de instituciones bancarias, entidad creada en 1978 por el Banco de España y la banca privada para enfrentar la crisis bancaria de finales de la década de 1970. La fórmula empleada fue especial - privada-: la toma de control del Banco Urquijo por su principal accionista, el Banco Hispano Americano, a la que este accedió bajo fuertes presiones del regulador bancario (Banco de España) y del propio gobierno español (el Partido Socialista Obrero Español acababa de ganar las elecciones generales en el otoño de 1982). En efecto, el Banco Hispano Americano logró el control del Banco Urquijo mediante la presentación de una oferta pública de adquisición de acciones,

\footnotetext{
${ }^{10}$ Empresas cotizadas se refiere a las que tenían su capital representado por acciones (títulos de renta variable) que podían ser intercambiadas (compradas y vendidas) por sus propietarios en el mercado bursátil. Algunas de ellas emitían también deuda en forma de bonos u obligaciones (títulos de renta fija), que eran también susceptibles de ser intercambiados en dicho mercado.
} 
y se comprometió a sanearlo con un plan pactado con el Banco de España (Cuervo, 1988, pp. 133-134). A partir de este momento, la historia del Banco Urquijo siguió unos derroteros muy distintos a los del periodo 1918-1982. Sus participaciones industriales fueron vendidas y el grupo Urquijo desapareció como tal, no así algunas de sus empresas más emblemáticas que hoy aún son referentes en sus respectivos sectores, como Duro Felguera, Construcción y Auxiliar de Ferrocarriles (CAF), Gas Natural o Técnicas Reunidas.

\section{Conclusiones}

El grupo Urquijo es un ejemplo representativo del modelo de grupos empresariales creados por bancos mixtos en España, especialmente por los más grandes (Banesto, Central, Bilbao, Vizcaya), desde el principio del siglo XX. En algunos casos, como ocurre con Banesto o el propio Urquijo, su origen se retrotrae al último cuarto del siglo XIX, cuando el país inició el camino de la industrialización, y refleja la influencia que recibieron de los bancos franceses de promoción industrial (Paribas, Rothschild), que tenían grandes intereses en España (minería, ferrocarriles, gas y electricidad). No obstante, la sociedad Urquijo y Compañía, primero, y el Banco Urquijo, después, llevaron la estrategia de la promoción industrial hasta cotas que no alcanzó ninguna otra entidad bancaria en España, convirtiéndose así en el banco industrial por antonomasia en el segundo tercio del siglo XX.

Como prototipo de esta clase de grupos, el grupo Urquijo estaba formado por una sociedad de cabecera o holding (Urquijo y Compañía desde 1883 y el Banco Urquijo desde 1918) poseedor de participaciones de diferente cuantía en el capital de un amplio conjunto de empresas (creadas o no por él) presentes en diferentes sectores no siempre relacionados. El compromiso del Banco Urquijo con estas empresas no era meramente financiero (búsqueda de la rentabilidad financiera de su inversión), sino estratégico y permanente, lo que lo llevó a responsabilizarse directamente de la gestión de las firmas en las que estaba más involucrado o a participar activamente en el control de la gestión de las demás mediante la presencia de sus representantes en los respectivos consejos de administración.

El compromiso estratégico del Banco Urquijo con su grupo de empresas incluye varios elementos que deben ser subrayados. Está, en primer lugar, su capacidad para proporcionales financiación básica (capital en acciones y obligaciones, préstamos y avales) y servicios bancarios (crédito comercial, gestión de tesorería, depósito de valores, etc.). Para esta labor, el Banco Urquijo utilizó también medios adicionales importantes, tales como la creación de bancos filiales y de sociedades de cartera y/o de inversión, la alianza con el Banco Hispano Americano o la canalización de inversión 
extranjera, una constante durante toda su existencia. Este último aspecto, en segundo lugar, va estrechamente unido a la incorporación de tecnología y conocimiento procedentes del exterior, que las empresas del grupo Urquijo recibieron de manera habitual de sus socios extranjeros gracias a las relaciones que los responsables del Banco Urquijo mantuvieron desde siempre con bancos y compañías europeas y americanas. En tercer lugar, la capacidad de este para atraer a su estrategia empresarios de diferentes sectores y regiones, así como de agrupar a ingenieros y técnicos especializados (Servicios Técnicos), contribuyó a formar un capital humano valioso y muy útil, no sólo para impulsar iniciativas de creación de empresas, sino también para abordar con más garantía las mayores exigencias técnicas y de gestión del conjunto de firmas de grupo Urquijo. Un complemento decisivo al respecto lo constituyen los Servicios de Estudios, cuyos análisis económicos ayudaron en la toma de decisiones sobre nuevas inversiones, en la reorganización de empresas y en la mejora de su competitividad, entre otras cosas. Por último, una contribución destacable del Banco Urquijo al desarrollo a largo plazo de su grupo de empresas lo constituye su capacidad para establecer contactos con las instituciones políticas y administrativas del país, lo que facilitó la realización de proyectos empresariales donde la presencia de inversores extranjeros era determinante.

El carácter familiar del Banco Urquijo y de la casa de banca que está en su origen es otro rasgo distintivo, pues guarda relación con la longevidad del proyecto bancario e industrial que definieron las dos primeras generaciones de la familia Urquijo y que continuaron las tres siguientes a lo largo de más de un siglo. El lema de contribuir activamente a la industrialización del país fue una seña de identidad de Casa Urquijo, que guió la conducta de cada una de las generaciones que asumieron la responsabilidad de su gestión. Cierto es que no todos los tránsitos generacionales estuvieron exentos de dificultades, pero también lo es que, cuando las hubo, se arbitraron soluciones que aseguraron la continuidad del proyecto. En estas soluciones fueron decisivas personas ajenas a la familia, como Ruiz Senén o Lladó, quienes interpretaron fielmente las señas de identidad de la Casa Urquijo.

Por lo anterior, la crisis final del Banco Urquijo y el desmantelamiento de su grupo de empresas a partir de 1982 pueden explicarse debido a la adversa coyuntura industrial y económica por la que atravesó España entre 1975 y 1982, aunada a la incertidumbre que generó el proceso de transición a la democracia y el cambio en el marco regulador de la actividad bancaria, pero también por la ausencia de consenso interno sobre la continuidad del modelo de banco industrial y la pérdida de otras señas de identidad relacionadas con el funcionamiento y la organización interna del Banco Urquijo, motivada por el espectacular crecimiento que experimentó a partir del decenio de 1960. 


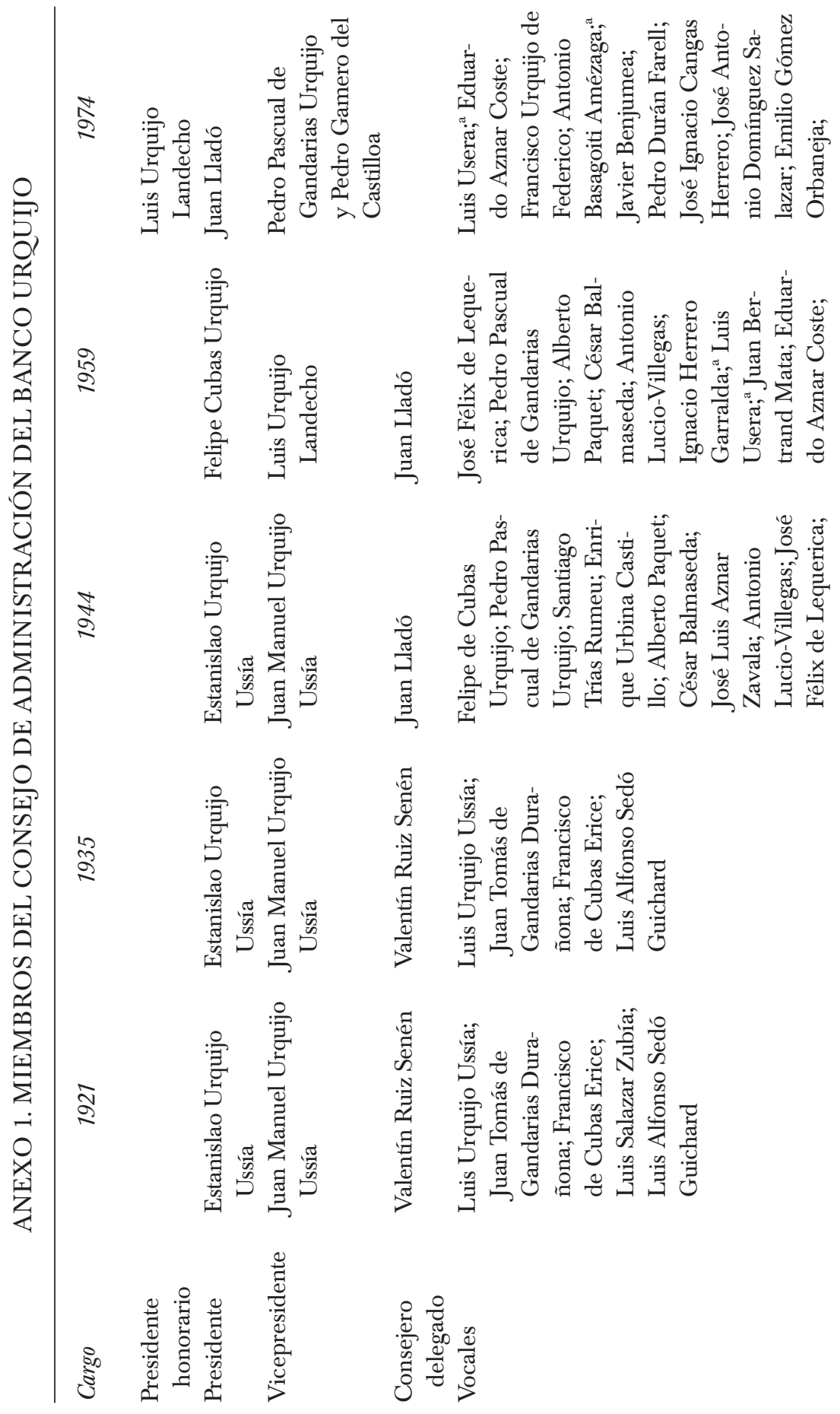




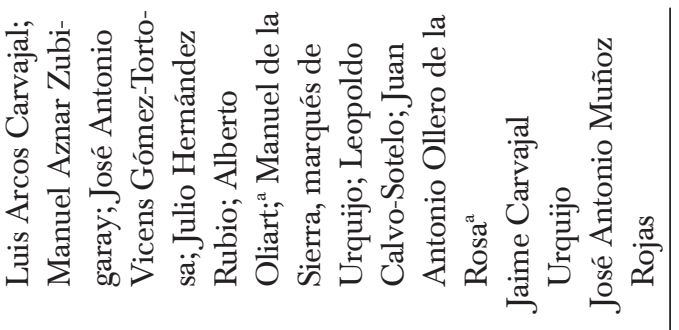
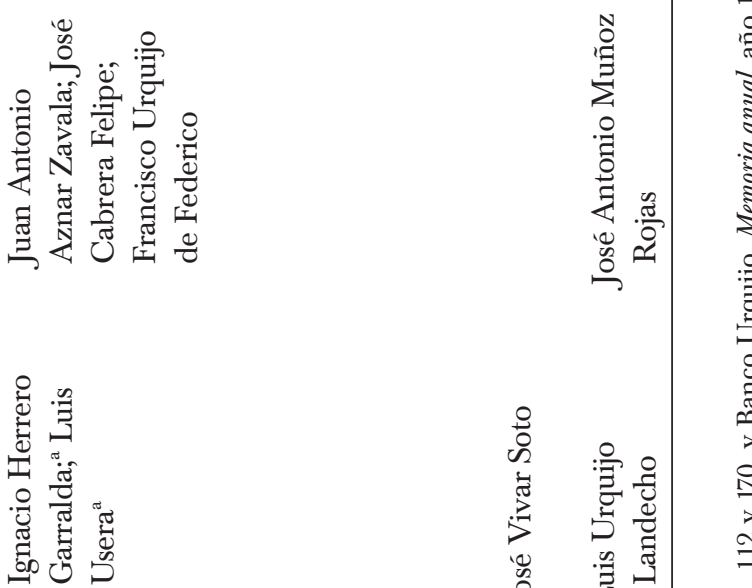

-

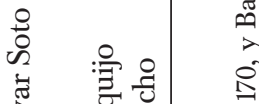

?

峁

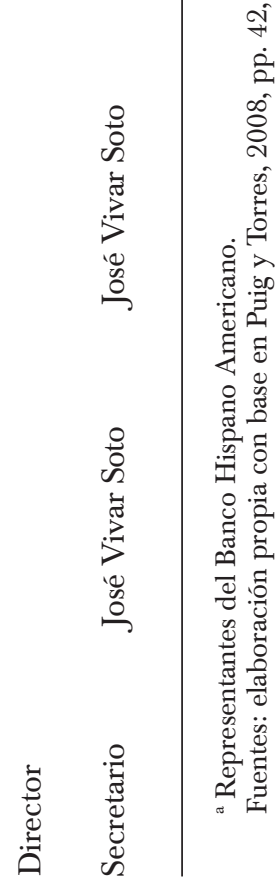




\section{LISTA DE REFERENCIAS}

Amsden, A. y Hikino, T. (1994). Project execution capability, organizational knowhow and conglomerate corporate growth in late industrialization. Industrial and Corporate Change, 3(1), 111-147.

Anes, R. (1999). La constitución de la Compañía Hispano-Americana de Electricidad. En Doctor Jordi Nadal. La industrialización y el desarrollo económico de España (2 vols., pp. 1344-1355). Barcelona: Universitat de Barcelona.

Anuario financiero y de sociedades anónimas de España (Años 1917, 1920, 1930, 1935, 1945, 1950 y 1960). Madrid: Editorial Sopec.

BANCo UrQujo (años 1921-1982). Memoria anual. Biblioteca del Banco de España, Madrid.

Bartolomé, I. (2007). La industria eléctrica en España (1890-1936). Madrid: Banco de España/Estudios de Historia Económica.

Carreras, A. y Tafunell, X. (1993). La gran empresa en España (1917-1974). Revista de Historia Industrial, 3, 127-175.

Castro, R. (2010). Génesis y transformación de un modelo de inversión internacional: el capital francés en la España del siglo XX (Tesis doctoral). Universidad Complutense, Madrid.

Colpan, A. M., Hikino, T. y Lincoln, J. R. (eds.) (2010). Oxford handbook of business groups. Reino Unido: Oxford University Press.

Comín, F., Martín, P., Muñoz, M. y Vidal, J. (1998). 150 años de historia de los ferrocarriles españoles. Madrid: Fundación de los Ferrocarriles Españoles/Anaya.

Cuervo, Á. (1988). La crisis bancaria en España, 1977-1985: causas, sistemas de tratamiento y coste. Barcelona: Ariel.

DíAZ, O. (1998). Los marqueses de Urquijo. El apogeo de una saga poderosa y los inicios del Banco Urquijo, 1870-1931. Pamplona: Ediciones Internacionales Universitarias.

Explosivos Río Tinto. Memoria anual. Año 1974. Biblioteca del Banco de España, Madrid.

Gerschenkron, A. (1968). El atraso económico en su perspectiva histórica. Barcelona: Ariel.

Houpt, S. y Ortiz-Villajos, J. M. (dirs.) (2002). Astilleros españoles, 1872-2000, Madrid: Lid/Izar.

HoYo, J. DEL y EscriñA, J. M. (2003). Javier Benjumea Puigcerver (1915-2001). Madrid: Edición de los autores.

Kock, C. J. y Guillén, M. F. (2001). Strategy and structure in developing countries: Business groups as an evolutionary response to opportunities for unrelated diversification. Industrial and Corporate Change, 10(1), 77-113.

Lladó, J. (1972). Informe sobre el Banco Urquijo. Congreso de la Federación Europea de Analistas Financieros. Madrid.

MARTín, P. y COMín, F. (1991). INI, 50 años de industrialización en España. Madrid: Espasa Calpe. 
MarTínez, R. (1971). Crédito y banca en España: análisis y estructura. Madrid: Editorial Moneda y Crédito.

Muñoz, J. (1970). El poder de la Banca en España. Madrid: Zero.

OJEDA, G. (2000). Duro Felguera: historia de una gran empresa industrial. Oviedo: Grupo Duro Felguera.

Pueyo, J. (2006). Relaciones interempresariales y consejeros comunes en la banca española del siglo XX. Investigaciones de Historia Económica, 6, 137-170.

Puig, N. y Torres, E. (2008). Banco Urquijo, un banco con historia. Madrid: Turner.

Puig, N. y Torres, E. (2011). El Grupo Urquijo y el desarrollo económico de España, 1918-1982. X Congreso Internacional de la AEHE. Sevilla. Recuperado de http://www. aehe.net/xcongreso/pdf/sesiones/grupo/el $\% 20$ grupo $\% 20$ urquijo $\% 20 y \% 20$ el $\% 20$ desarrollo\%20economico.pdf

Rodrigo, M. (2001). Los marqueses de Comillas, 1817-1925. Antonio y Claudio López. Madrid: Lid.

RuedA, J. C. (1996). Préstamo y finanzas durante la segunda mitad del siglo XIX: una aproximación a la figura de los Urquijo. Historia Contemporánea, 13-14, 297-322.

SAN Román, E. (1999). Ejército e industria. El nacimiento del INI. Barcelona: Crítica.

Toboso, P. (2000). Pepín Fernández, 1891-1982. Galerías Preciados. El pionero de los grandes almacenes. Madrid: Lid.

Tortella, G. y García, J. L. (1999) Una historia de los Bancos Central e Hispano Americano: un siglo de gran banca en España. Manuscrito sin publicar. Cortesía de los autores.

VALDALiSO, J. M. (2004). Grupos empresariales y relaciones banca-industria en España durante el franquismo: una aproximación microeconómica. Información Comercial Española, 812, 163-178.

VAldaliso, J. M. (2006). La familia Aznar y sus negocios (1830-1983). Cuatro generaciones de empresarios en la España contemporánea. Madrid: Marcial Pons.

VIDAL, J. (1999). La estructura de la propiedad, la organización y la gestión de una gran empresa ferroviaria: Compañía de los Caminos de Hierro del Norte de España, 1858-1936. Revista de Historia Económica, 17(3), 623-662. 